\title{
A High-Temperature Transient Hot-Wire Thermal Conductivity Apparatus for Fluids
}

\section{R. A. Perkins and H. M. Roder}

National Institute of Standards and Technology, Boulder, CO 80303

and

\section{A. Nieto de Castro ${ }^{1}$}

Departamento de Quimica, Universidade de Lisboa, R. Ernesto Vasconcelos, Bloco Cl, 1700 Lisboa, Portugal
A new apparatus for measuring both the thermal conductivity and thermal diffusivity of fluids at temperatures from 220 to $775 \mathrm{~K}$ at pressures to $70 \mathrm{MPa}$ is described. The instrument is based on the step-power-forced transient hot-wire technique. Two hot wires are arranged in different arms of a Wheatstone bridge such that the response of the shorter compensating wire is subtracted from the response of the primary wire. Both hot wires are $12.7 \mu \mathrm{m}$ diameter platinum wire and are simultaneously used as electrical heat sources and as resistance thermometers. A microcomputer controls bridge nulling, applies the power pulse, monitors the bridge response, and stores the results. Performance of the instrument was verified with measurements on liquid toluene as well as argon and nitrogen gas. In particular, new data for the thermal conductivity of liquid toluene near the saturation line, between 298 and $550 \mathrm{~K}$, are presented. These new data can be used to illustrate the importance of radiative heat transfer in transient hotwire measurements. Thermal conductivity data for liquid toluene, which are corrected for radiation, are reported. The precision of the thermal conductivity data is $\pm 0.3 \%$ and the accuracy is about $\pm 1 \%$. The accuracy of the thermal diffusivity data is about $\pm 5 \%$. From the measured thermal conductivity and thermal diffusivity, we can calculate the specific heat, $C_{p}$, of the fluid, provided that the density is measured, or available through an equation of state.

Key words: argon; heat capacity; nitrogen; radiation correction; thermal conductivity; thermal diffusivity; toluene; transient hot-wire.

Accepted: March 5, 1991

\section{Introduction}

The transient hot-wire method is widely accepted as the most accurate technique for fluid thermal conductivity measurements at physical states removed from the critical region proper [1]. The method is very fast relative to steady state techniques. The duration of a typical experiment is about $1 \mathrm{~s}$ when 250 temperature rises are measured. Normally the experiment is completed before free convection can develop in the fluid. If free convection is present, it is easy to detect be-

\footnotetext{
${ }^{1}$ Also Centro de Quimica Estrutural, Complexo I, IST, 1096 Lisboa Codex, Portugal.
}

cause it results in a pronounced curvature in the graph of temperature rise versus the logarithm of time.

In addition to the thermal conductivity, thermal diffusivity can be measured with transient hot-wire instruments. With an appropriate design of the instrument [2], measurements of fluid thermal diffusivity can be made with reasonable accuracy over wide ranges of density. The heat capacity of a fluid can then be obtained from the measurements of thermal conductivity and thermal diffusivity, provided that the density is known or available from an equation of state. 


\section{Method}

The transient hot-wire system is considered to be an absolute primary instrument [1]. The ideal working equation is based on the transient solution of Fourier's law for an infinite linear heat source [3]. The temperature rise of the fluid at the surface of the wire, where $r=r_{0}$, at time $t$ is given by

$$
\begin{aligned}
& \Delta T_{\text {ideal }}\left(r_{1}, t\right)=\frac{q}{4 \pi \lambda} \ln \left(\frac{4 a t}{r_{0}^{2} C}\right)=\frac{q}{4 \pi \lambda} \ln \left(\frac{4 a}{r_{0}^{2} C}\right) \\
& +\frac{q}{4 \pi \lambda} \ln (t) .
\end{aligned}
$$

In eq (1), $q$ is the power input per unit length of wire, $\lambda$ is the thermal conductivity, $a=\lambda / \rho C_{p}$ is the thermal diffusivity of the fluid, $\rho$ is the density, $C_{p}$ is the isobaric heat capacity, and $C=\mathrm{e}^{\gamma}=1.781 \ldots$ is the exponential of Euler's constant. We use eq (1) and deduce the thermal conductivity from the slope of a line fit to the $\Delta T_{\text {ideal }}$ versus $\ln (t)$ data. The working equation for the thermal diffusivity is

$$
a=\frac{r_{0}^{2} C}{4 t^{\prime}} \exp \left[\frac{4 \pi \lambda \Delta T_{\text {ideal }}\left(r_{0} t^{\prime}\right)}{q}\right] .
$$

The thermal diffusivity is obtained from $\lambda$ and a value of $\Delta T_{\text {ideal }}$, from the fit line, at an arbitrary time $t^{\prime}$. We normally select $t^{\prime}$ to be $1 \mathrm{~s}$ in our data analysis, as discussed in reference [2].

The thermal conductivity is reported at the reference temperature $T_{\mathrm{r}}$ and density $\rho_{\mathrm{r}}$ defined in eq (3) below. The thermal diffusivity calculated from eq (2) must be referred to zero time, that is, the equilibrium or cell temperature. In summary, the thermal conductivity and the thermal diffusivity evaluated by the data reduction program are related to the reference state variables and to the zero time cell variables as follows:

$$
\begin{aligned}
& \lambda=\lambda\left(T_{\mathrm{r}}, \rho_{\mathrm{r}}\right), \\
& T_{\mathrm{r}}=T_{0}+0.5\left(\Delta T_{\text {initial }}+\Delta T_{\text {final }}\right), \\
& \rho_{\mathrm{r}}=\rho\left(T_{\mathrm{r}}, P_{0}\right), \\
& a=a\left(\rho_{0}, T_{0}\right)=\frac{\lambda\left(T_{\mathrm{u}}, \rho_{0}\right)}{\rho_{0}\left(C_{p}\right)_{0}}, \\
& \rho_{0}=\rho\left(T_{0}, P_{0}\right), \text { and } \\
& \left(C_{p}\right)_{0}=C_{p}\left(T_{0}, P_{0}\right),
\end{aligned}
$$

where $T_{0}$ is the equilibrium temperature and $P_{0}$ is the equilibrium pressure at time $t=0$.

The experimental apparatus is designed to approximate the ideal model as closely as possible. There are, however, a number of corrections which account for deviations between the ideal linesource heat transfer model and the actual experimental heat transfer situation. The ideal temperature rise is obtained by adding a number of corrections to the experimental temperature rise as

$$
\Delta T_{\text {ideal }}=\Delta T_{\text {experimental }}+\sum_{i} \delta T_{i}
$$

These temperature rise corrections are described in references $[2,4]$. Our implementation of the corrections follows these two references with the exception of the thermal radiation correction. This correction is dependent on the optical properties of the fluid and the cell, and is discussed in more detail below.

\subsection{The Radiation Correction}

If the fluid is transparent to infrared radiation, then this correction is only a function of the cell geometry and the optical properties of the materials used in its construction. The radiation correction described in references $[2,4]$ assumes that all of the surfaces in the cell are blackbodies. The blackbody radiation correction is given by

$$
\delta T_{5 \mathrm{r}}=\frac{8 \pi r_{0} \sigma T_{0}^{3} \Delta T^{2}}{q}
$$

where $\sigma$ is the Stefan-Boltzmann constant. In practice, many experimenters assume that this correction is negligible and neglect the correction. We have found that this correction changes the reported thermal conductivity of argon at $300 \mathrm{~K}$ by about $1 \%$ for our geometry, so it is not appropriate to ignore it. A more accurate correction can be obtained by considering the optical properties of the surfaces in the hot-wire cell.

For this analysis we consider the cell surfaces to be diffuse gray surfaces and follow the analysis presented in reference [5]. We consider the cell to be an infinitely long hot wire in a concentric cylindrical cavity. Thus, two surfaces are involved in the heat transfer. Surface 1 is the hot wire whose temperature is a function of time, and surface 2 is the cylindrical cavity surrounding the hot wire which remains at the initial equilibrium temperature. The net radiative heat flux for the hot wire, using the tabulated view factors in reference [5], is

$$
Q_{1}=\frac{A_{1} \mathbf{\sigma}\left(T_{1}^{4}-T_{2}^{4}\right)}{\frac{1}{\epsilon_{1}}+\frac{A_{1}}{A_{2}}\left(\frac{1}{\epsilon_{2}}-1\right)}
$$


where $A_{i}$ is the area, $T_{i}$ is the temperature, and $\epsilon_{i}$ is the emissivity of surface $i$. The ratio of the surface areas $A_{1} / A_{2}$ which is present in the denominator of eq (6) is quite small since very thin hot wires are used. In our cell this surface area ratio is $A_{1} /$ $A_{2}=0.001$. The inverse emissivity of the hot wire $1 / \epsilon_{1}$ varies from 10 to 25 for platinum and $1 / \epsilon_{2}$ is approximately 2 . Therefore, the second term in the denominator of eq (5) is negligible to within $0.1 \%$ in $Q_{1}$, and we are left with

$$
Q_{1}=A_{1} \epsilon_{1} \sigma\left(T_{1}^{4}-T_{2}^{4}\right) .
$$

Because the surface area of the cavity surrounding the hot wire is so much larger than the surface area of the hot wire, to a first approximation the heat transfer is not a function of the emissivity of the cavity. ${ }^{2}$ The cavity appears to be a blackbody, and the heat transfer is only a function of the emissivity of the platinum hot wire. Following the analysis of reference [4], the resulting correction to the experimental temperature rise in a transparent fluid is

$$
\delta T_{5 \mathrm{~T}}=\frac{8 \pi r_{0} \epsilon_{\mathrm{platinum}} \sigma T_{0}^{3} \Delta T^{2}}{q}
$$

The emissivity of platinum, $\epsilon_{\text {platinum }}$, is a function of temperature and is tabulated in reference [6]. At $300 \mathrm{~K}$ the emissivity of platinum is 0.0455 relative to an emissivity of 1 for a blackbody. The blackbody radiation correction of eq (5) is roughly 20 times larger than the real case, eq (8), when platinum hot wires are used.

For fluids which absorb infrared radiation, the technique described in reference [7] works well. The technique is based on the numerical simulations of transient conduction and radiative heat transfer from a hot wire in an absorbing medium. Since the emissivity of the platinum hot wire is so small, the radiative heat flux from the wire is negligible in the simulations. The primary mechanism for radiative losses is from emission from the fluid at the boundary of the expanding conduction front. This analysis [7] yields a radiation correction for absorbing media which is given by

$$
\delta T_{5 \mathrm{~A}}=-\frac{q B}{4 \pi \lambda}\left[\frac{r_{0}^{2}}{4 a} \ln \left(\frac{4 a t}{r_{0}^{2} \mathrm{C}}\right)+\frac{r_{0}^{2}}{4 a}-t\right] .
$$

\footnotetext{
${ }^{2}$ This is possible because, as shown later, $Q_{1} / L q=2 \times 10^{-2}$ for the transient hot-wire instrument and, therefore, an error of $0.1 \%$ in $Q_{1}$ produces an error of $0.002 \%$ in $q$, well beyond the experimental accuracy.
}

The radiation parameter $B$ is related to the fluid properties by

$$
B=\frac{16 K n^{2} \sigma T_{0}^{3}}{\rho C_{p}},
$$

where $K$ is the mean extinction coefficient of the fluid and $n$ is its refractive index. These fluid properties are a function of the fluid density and temperature and are not generally available. The procedure described in reference [7] allows $B$ to be estimated from the experimental temperature rise data. Equation (9) indicates that the radiation correction introduces a term which is a direct function of time into the temperature rise equation. When the radiation correction is added to the ideal temperature rise, we obtain

$$
\Delta T=\frac{q}{4 \pi \lambda}\left[1+\frac{B r_{0}^{2}}{4 a}\right] \ln \left(\frac{4 a t}{r_{0}^{2} C}\right)-\frac{B q t}{4 \pi \lambda}+\frac{B q r_{0}^{2}}{16 \pi a \lambda}+\ldots .
$$

Thus, we correct the experimental data with all the other corrections and fit the resulting temperature rise to a function of the form

$$
\Delta T=C_{1} \ln (t)+C_{2} t+C_{3} .
$$

The experimental radiation parameter $B$ is determined from coefficient $C_{2}$ using

$$
B=C_{2}\left(\frac{-4 \pi \lambda}{q}\right)
$$

Once $B$ is determined, we use eq (9) to correct for radiation in the absorbing fluid. This technique allows us, as shown later, to use our experimental data to determine whether there is a significant thermal radiation correction in an absorbing fluid and to correct for the radiation. No prior knowledge of the optical properties of the fluid is required.

\section{Apparatus}

The apparatus is quite similar to a previously described low temperature system [8] which is used from 80 to $320 \mathrm{~K}$. The new apparatus is designed to operate from 220 to $750 \mathrm{~K}$ at pressures to $70 \mathrm{MPa}$. A preliminary version of the new instrument has been described elsewhere [9]. Improvements have been incorporated into the new system to improve the precision and accuracy of the thermal conduc- 
tivity measurement and to enable measurement of the thermal diffusivity. They were based on modifications introduced in the low temperature system which are fully described in references [10] and [11].

\subsection{Hot Wires}

The hot wires are selected to conform to the ideal line-source model as closely as possible. The line-source model assumes that the wire has no heat capacity and that it is infinitely long, so there is no axial heat conduction. The wire diameter is $12.7 \mu \mathrm{m}$ in this instrument to minimize effects due to its finite heat capacity while retaining good tensile strength and uniformity. A two-wire compensating system is used in order to eliminate effects due to axial heat conduction. The arrangement of the two wires is shown in figure 1 . The two wires have different lengths and are arranged in a modified Wheatstone bridge where the thermal response of the short wire is subtracted from the response of the long wire. The resulting response from a finite length of wire approximates that of an infinitely long hot wire. The length of the equivalent wire is the difference in the lengths of the long and short hot wires.

The hot wires are used simultaneously as electrical heat sources and as resistance thermometers.

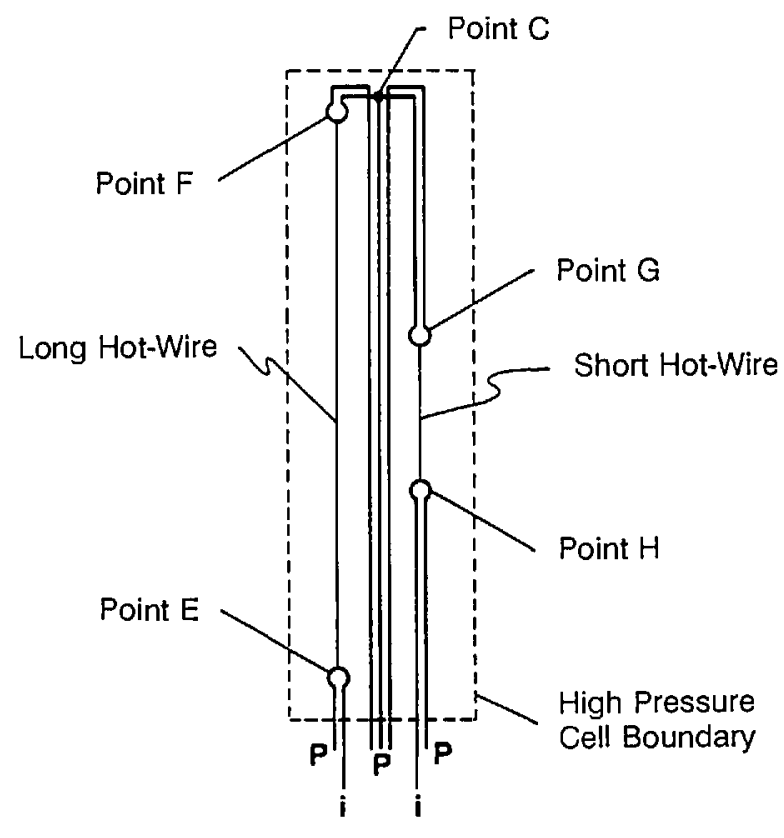

Figure 1. Arrangement of current leads (i) and potential taps (P) within the pressure cell. Bridge points correspond to those in figure 3.
Platinum wire is used in this instrument because its mechanical and electrical properties are well known over a wide temperature range, and it is resistant to corrosion up to $750 \mathrm{~K}$. As shown above, platinum has the added advantage of low emissivity. The length of the long hot wire is about $19 \mathrm{~cm}$. The length of the short hot wire is about $5 \mathrm{~cm}$. The platinum hot wires are annealed after they are installed, so that their resistance will be stable during high temperature operation. The resistance of the annealed hot wires is about $20 \%$ less than the harddrawn platinum wire. The resistance of the hot wires is calibrated in situ as a function of temperature and pressure [12].

The wires are welded to rigid upper suspension stirrups and weighted lower suspension stirrups. The floating lower weights are used to tension the wires and to allow for thermal expansion. There are fine copper wires welded between the bottom weights and the massive bottom leads. These fine wire leads are flexible so that they do not introduce significant stress on the platinum hot wires. This arrangement provides both current and potential leads to both ends of each hot wire. Thus, four-terminal resistance measurements can be made on both the long and short hot wires, eliminating uncertainty due to lead resistances.

\subsection{Hot-Wire Cell}

The two platinum hot wires are contained in a pressure vessel which is designed for $70 \mathrm{MPa}$ at 750 $\mathrm{K}$. The cell is connected with a capillary tube to a sample-handling manifold. This sample-handling manifold allows evacuation of the cell, charging and pressurization of liquids with a screw pump, and pressurization of gases with a diaphragm compressor. There are seven electrical leads into the pressure vessel to enable four-terminal resistance measurements of both hot wires. The electrical leads pass through a $6.25 \mathrm{~mm}$ O.D. pressure tube which connects the bottom of the pressure vessel to the lead pressure seal. The pressure seal for the electrical leads is made at ambient temperature for improved reliability. The vessel access tube is located on the bottom of the vessel so that there is always a positive temperature gradient with respect to height to eliminate free convective driving forces. The entire pressure system is constructed of $\mathbf{3 1 6}$ stainless steel for corrosion resistance.

The thermal conductivity cell is shown in its temperature control environment in figure 2 . The cell pressure vessel is surrounded by a $12 \mathrm{~mm}$ thick cylindrical aluminum heat shield. The aluminum 


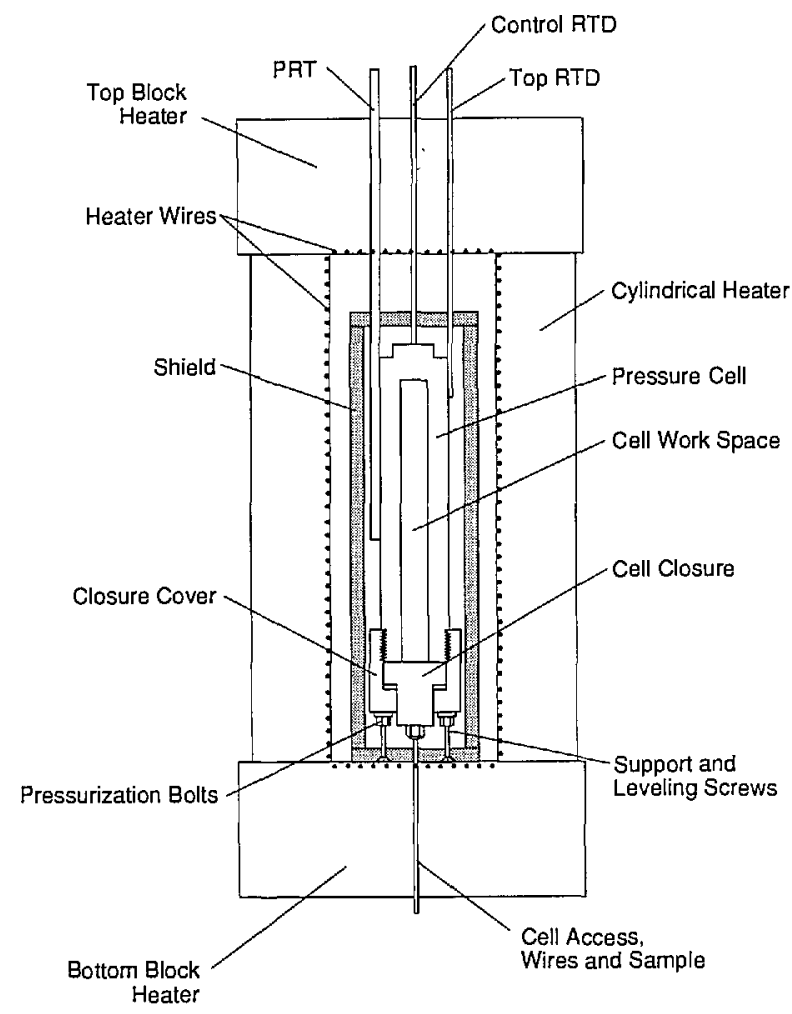

Figure 2. High-pressure cell, shield, and furnace.

has a high thermal conductivity and provides a nearly isothermal environment for the pressure vessel. There is an air gap between the vessel and the heat shield. This air gap isolates the pressure vessel from temperature fluctuations in the heat shield. Tubes are silver-soldered to the outside of the pressure vessel which enclose the reference standard platinum resistance thermometer (PRT) and two smaller platinum resistance probes (RTDs). The two RTDs can be moved axially along the vessel to detect temperature gradients. Normally, one RTD is located near the top of the vessel, and the other RTD is located near the bottom of the vessel. This configuration allows us to measure the cell temperature at the center of the vessel with the reference standard PRT and temperature gradient in the cell with the two RTDs for each thermal conductivity measurement.

For experiments from ambient temperature to $750 \mathrm{~K}$, the vessel and heat shield are placed in a cylindrical furnace constructed of heating elements cast in fibrous ceramic insulation. These heating elements are shown in figure 2 and are separated from the aluminum heat shield by a second air gap. An additional platinum RTD is located on the top of the aluminum heat shield. This probe provides the feedback signal for the furnace temperature control system. The main power supply is under computer control and is connected to the bottom end heating element and the tubular heating elements. The second trim power supply is manually controlled to eliminate axial gradients in the thermal conductivity cell. The heating elements are driven with dc power supplies to minimize electromagnetic noise in the thermal conductivity instrument. Temperature fluctuations in the cell are normally less than $0.01 \mathrm{~K}$.

For experiments between 220 and $300 \mathrm{~K}$, the electrical heaters are replaced by a copper cooling coil enclosed in polystyrene insulation. A refrigerant with a low freezing point is pumped through the cooling coil by a recirculating temperature control bath. This recirculating bath controls the fluid temperature to within $0.01 \mathrm{~K}$. The aluminum heat shield and air gap further reduce the temperature fluctuations in the cell to less that $0.01 \mathrm{~K}$.

\subsection{Wheatstone Bridge Circuit}

This instrument uses a Wheatstone bridge circuit to monitor the resistance changes of the hot wires during the step-power pulse. The two hot wires are set up in opposing legs of the Wheatstone bridge as shown in figure 3 . The drive voltage is applied across points $A$ and $B$. The bridge response is monitored by a high speed digital multimeter across points $\mathrm{C}$ and $\mathrm{D}$. The bridge is initially balanced with a $100 \mathrm{mV}$ drive voltage. There is negligible heating of the hot wires with this small balance voltage. The four legs of the Wheatstone bridge are designated R1, R2, R3, and R4. Each of the four legs contains a variable decade resistor. The smallest step on these decade resistors is $0.01 \Omega$. These four decade resistors are adjusted so that the bridge imbalance signal is 0 and the total resistance of each leg is the same.

There are two current paths between points $A$ and B. Each current path contains a calibrated 100 $\Omega$ standard resistor in order to determine the current flowing through that path during the balancing procedure. Figure 3 shows a number of voltage taps on the Wheatstone bridge which allow the multiplexed digital multimeter to measure the voltage drops across all of the resistances in the bridge. Using the current, provided by the voltage drop across the standard resistors, we can obtain the resistance of all of the components of the bridge.

These resistances must be known very precisely, and the bridge must be balanced very closely, in 


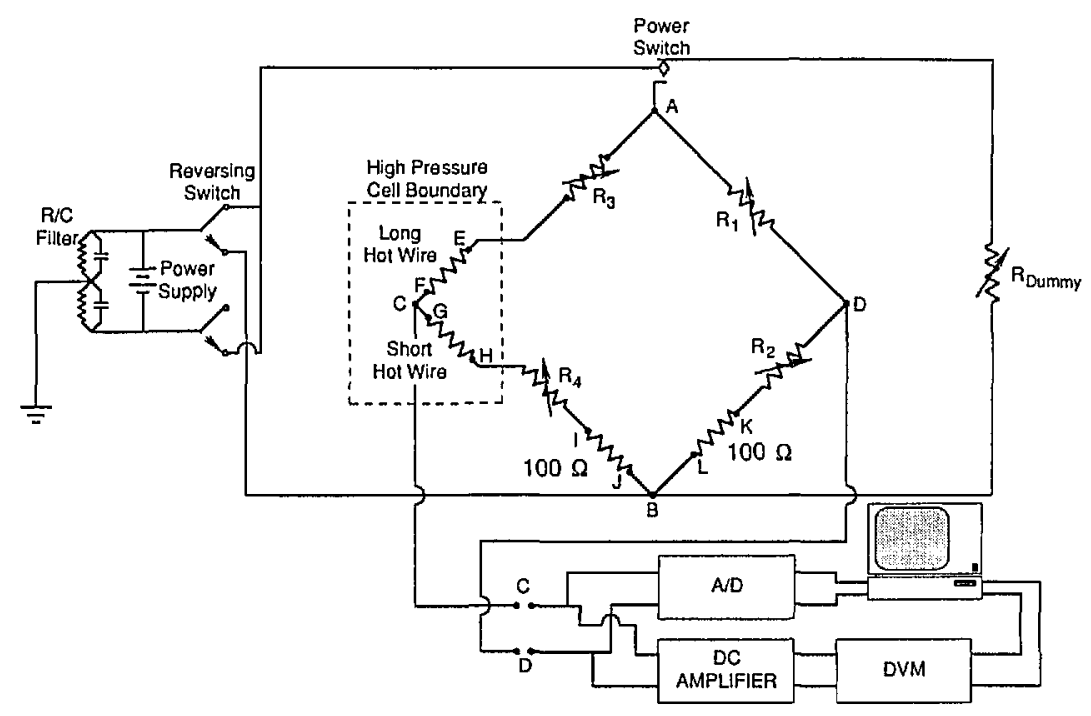

Figure 3. The Wheatstone bridge schematic for the transient hot-wire apparatus. Potential taps are indicated by points $\mathrm{A}-\mathrm{L}$.

order to obtain accurate thermal diffusivities from the experiment. Thermal voltages from the components of the bridge have a significant impact on the balancing of the bridge. In order to eliminate errors from thermal voltages, the bridge is alternately measured with a positive and negative drive voltage with a reversing relay. During the balancing procedure, 10 alternating drive voltage cycles are measured. During each cycle the digital multimeter monitors the voltage across all of the voltage taps. These values are subsequently averaged and displayed by the system computer.

When a satisfactory bridge balance is obtained, we are ready to begin the transient hot-wire experiment. The power supply is switched to a dummy resistor and the drive voltage is set to a level which will produce the desired heating of the hot wires. The experiment begins when the power supply is switched from the dummy resistor to the Wheatstone bridge. During the experiment the multimeter records the bridge voltage as a function of time across points $C$ and $D$. This signal is proportional to the differential resistance change of the two hot wires. This differential resistance change of the two wires is related to the temperature changes of the two hot wires by the wire calibration which is described below. The experiment normally lasts $1 \mathrm{~s}$ with a bridge response voltage recorded every $4 \mathrm{~ms}$.

\subsection{Data Acquisition and Control}

Data acquisition and control are coordinated by a personal computer. The computer controls the cell temperature, synchronizes the experimental timing, records the data, and provides a graphical display of the data. The computer has an analogto-digital interface board which generates the timing signals based on the computer's internal quartz crystal oscillator and controls the system voltage multiplexers. The computer is also equipped with an IEEE-488 interface which allows communication with a dedicated digital temperature controller, a digital nanovoltmeter, and the high speed digital multimeter.

The cell PRT and the two gradient RTDs are connected in series with a standard resistor and a precision $1 \mathrm{~mA}$ current source. The computer controls a multiplexer which allows the nanovoltmeter to measure the voltage drops across the three resistance thermometers and the calibrated standard resistor. Using the current which is determined by the voltage drop across the standard resistor, we can obtain the resistances of the three thermometers.

A second multiplexer is connected to the input of the high speed digital multimeter. This multiplexer allows sampling of all the voltage taps on the Wheatstone bridge during bridge balancing. Since standard resistors are included in both current paths of the bridge, we can obtain accurate measurements of all the resistances in the bridge. The resistance of the two hot wires is used in conjunction with the PRT temperature to obtain the calibrations for the hot wires. In addition, the multiplexer allows us to measure the drive voltage and the resistance of the power switching relay for 
an accurate determination of the power applied to the hot wires.

During the experiment, there are two parallel systems measuring the bridge response. A 16 bit analog-to-digital converter directly monitors the bridge response, while the high speed digital multimeter monitors the response of an instrumentation amplifier which is also connected across points $\mathrm{C}$ and $D$. The instrumentation amplifier has a fixed gain of 100 and also has an analog filter built in. This filter significantly reduces the noise of the bridge response but introduces a time lag which we must account for. The noise of the raw signal is 25 $\mu V$ but is reduced to $3 \mu V$ by the filter. The experimental timing is fixed by the raw signal which is monitored by the analog-to-digital converter. The relatively noisy raw signal is used to adjust the timing of the filtered bridge response which is recorded by the high speed digital multimeter.

\section{Hot-Wire Calibration}

The electrical resistance of pure platinum as a function of temperature is very well characterized because of its widespread use in thermometry. In most thermometry applications the platinum is maintained at ambient pressure. In transient hotwire instruments, however, the platinum is immersed directly in the fluid of interest. Roder et al. [12] showed that the effect of pressure on the resistance of the platinum hot wires must be accounted for. The functional form of our calibration is given by

$$
R(T, P)=A+B T+C T^{2}+(D+E T) P,
$$

where $R$ is the wire resistance, $T$ is the temperature, and $P$ is the applied pressure.

We have found that an in situ calibration provides the most reliable measurements possible. In practice, we obtain the resistance of both hot wires at the cell temperature and pressure for every experiment. The calibration process is an integral part of balancing the bridge. As described above, we have the capability to make a four-terminal resistance measurement of each hot wire without errors from the temperature-dependent lead resistance. When we have completed all measurements on a given fluid, we do a surface fit of the resistance of each wire using the functional form above. Examining trends in deviations from this surface fit helps us to detect inconsistent data. Slow changes in the calibration usually indicate changes in the physical condition of the hot wires, such as contin- ued annealing of the platinum at high temperatures. Sudden changes in the wire calibration provide an indication of mechanical damage to the wires. In addition, the capability to generate an in situ calibration provides freedom to use materials other than platinum for the hot wires.

\section{Performance Verification}

Toluene was selected to verify the instrument performance in the liquid phase since it has been recently recommended as a thermal conductivity reference standard [13]. Argon and nitrogen were selected to verify performance of the apparatus in the gas phase since they have been widely studied with both steady-state techniques and transient hot-wire instruments. In addition, they have been studied with our low temperature instrument so that discrepancies between the two instruments can be detected and resolved.

\subsection{Toluene}

The thermal conductivity of liquid toluene has been widely studied with both steady-state and transient hot-wire instruments for a number of years. Early steady-state experiments on toluene were often plagued by free convection. Free convection is easily avoided in a transient hot-wire instrument, but, if present, is easily detected due to deviations from the ideal line-source model. The contribution of thermal radiation to the apparent thermal conductivity of toluene has also been of much concern since toluene is not transparent in the infrared. Nieto de Castro et al. [7] have made an extensive study of thermal radiation and concluded that the radiative contribution to heat transfer is very small for toluene at temperatures up to $370 \mathrm{~K}$. Above $370 \mathrm{~K}$, it was estimated that the contribution of heat transport by radiation to the measured value of thermal conductivity would increase with temperature resulting in nonzero values of the quantity $B$ in eq (13). Toluene was selected to verify both the performance of the new instrument in the liquid phase and the size and effect of the radiative contribution at the higher temperatures.

The spectroscopic grade toluene used in our verification measurements was dried over calcium hydride and distilled to remove a trace of benzene impurity. The purified toluene was analyzed by gas chromatography and found to have less than 50 parts per billion (ppb) benzene and less than 100 $\mathrm{ppb}$ water. The results of the saturated liquid toluene tests are provided in table 1 . In order to 
Table 1. Thermal conductivity, thermal diffusivity, and heat capacity of liquid toluene from 300 to $550 \mathrm{~K}$

\begin{tabular}{|c|c|c|c|c|c|c|c|c|}
\hline Run Pt. & $\begin{array}{l}\text { Pressure } \\
\mathrm{MPa}\end{array}$ & $\begin{array}{c}\text { Temperature } \\
\mathbf{K}\end{array}$ & $\begin{array}{l}\text { Density } \\
\mathrm{mol} / \mathrm{L}\end{array}$ & $\begin{array}{l}\text { Power } \\
\mathrm{W} / \mathrm{m}\end{array}$ & $\begin{array}{l}\text { Thermal } \\
\text { conductivity } \\
\text { W/(m/K) STAT }\end{array}$ & $\begin{array}{c}\text { Cell } \\
\text { temperature } \\
\mathbf{K}\end{array}$ & $\begin{array}{c}\text { Thermal } \\
\text { diffusivity } \\
\text { m²/s DSTAT }^{2}\end{array}$ & $\begin{array}{c}\text { Specific } \\
\text { heat } \\
\mathrm{J} /(\mathrm{mol} \cdot \mathrm{K})\end{array}$ \\
\hline 1101 & 0.090 & 302.441 & 9.3100 & 0.94731 & 0.128800 .000 & 297.811 & $0.866 \times 10^{-7} 0.003$ & 160.6 \\
\hline 1102 & 0.090 & 302.128 & 9.3131 & 0.87943 & 0.129180 .000 & 297.840 & $0.880 \times 10^{-7} 0.003$ & 158.4 \\
\hline 1103 & 0.090 & 301.835 & 9.3160 & 0.81210 & 0.128850 .000 & 297.872 & $0.861 \times 10^{-7} 0.004$ & 161.3 \\
\hline 1104 & 0.090 & 301.549 & 9.3188 & 0.74835 & 0.128650 .000 & 297.869 & $0.852 \times 10^{-7} 0.004$ & 162.7 \\
\hline 1105 & 0.090 & 301.265 & 9.3215 & 0.68819 & $0.12868 \quad 0.001$ & 297.891 & $0.858 \times 10^{-7} 0.005$ & 161.5 \\
\hline 1201 & 0.088 & 328.877 & 9.0466 & 0.96177 & 0.121450 .000 & 323.969 & $0.791 \times 10^{-7} 0.003$ & 170.8 \\
\hline 1202 & 0.088 & 328.528 & 9.0501 & 0.88883 & 0.121320 .000 & 324.039 & $0.789 \times 10^{-7} 0.003$ & 170.9 \\
\hline 1203 & 0.088 & 328.174 & 9.0537 & 0.81994 & 0.121440 .000 & 324.005 & $0.792 \times 10^{-7} 0.004$ & 170.2 \\
\hline 1204 & 0.088 & 327.841 & 9.0571 & 0.75378 & 0.121460 .000 & 323.979 & $0.788 \times 10^{-7} 0.004$ & 171.1 \\
\hline 1205 & 0.088 & 327.506 & 9.0605 & 0.69063 & 0.121660 .001 & 323.937 & $0.790 \times 10^{-7} 0.005$ & 170.7 \\
\hline 1206 & 0.089 & 327.180 & 9.0638 & 0.62968 & 0.121670 .001 & 323.951 & $0.786 \times 10^{-7} 0.006$ & 171.5 \\
\hline 1207 & 0.088 & 326.927 & 9.0664 & 0.57154 & 0.121710 .001 & 323.951 & $0.784 \times 10^{-7} 0.007$ & 171.9 \\
\hline 1208 & 0.088 & 326.638 & 9.0693 & 0.51693 & 0.122100 .001 & 323.927 & $0.795 \times 10^{-7} 0.007$ & 170.0 \\
\hline 1301 & 0.086 & 347.212 & 8.8572 & 0.45110 & 0.116260 .001 & 344.798 & $0.744 \times 10^{-7} 0.008$ & 177.1 \\
\hline 1302 & 0.086 & 349.371 & 8.8346 & 0.86369 & 0.115710 .000 & 344.881 & $0.745 \times 10^{-7} 0.003$ & 176.8 \\
\hline 1303 & 0.086 & 349.037 & 8.8381 & 0.79636 & 0.115730 .000 & 344.778 & $0.748 \times 10^{-7} \quad 0.003$ & 176.0 \\
\hline 1304 & 0.086 & 348.691 & 8.8417 & 0.73227 & 0.115950 .000 & 344.785 & $0.752 \times 10^{-7} 0.004$ & 175.3 \\
\hline 1305 & 0.086 & 348.357 & 8.8452 & 0.67060 & 0.115950 .000 & 344.788 & $0.749 \times 10^{-7} 0.004$ & 175.8 \\
\hline 1306 & 0.086 & 348.045 & 8.8485 & 0.61146 & 0.116070 .001 & 344.805 & $0.737 \times 10^{-7} 0.005$ & 178.7 \\
\hline 1307 & 0.086 & 347.756 & 8.8515 & 0.55506 & 0.116100 .001 & 344.821 & $0.734 \times 10^{-7} 0.006$ & 179.3 \\
\hline 1308 & 0.086 & 347.484 & 8.8544 & 0.50142 & 0.116130 .001 & 344.838 & $0.737 \times 10^{-7} 0.006$ & 178.6 \\
\hline 1401 & 0.129 & 372.502 & 8.5863 & 0.77696 & 0.109820 .000 & 368.375 & $0.701 \times 10^{-7} 0.003$ & 183.7 \\
\hline 1402 & 0.129 & 372.132 & 8.5904 & 0.71422 & 0.109710 .000 & 368.341 & $0.692 \times 10^{-7} 0.004$ & 185.7 \\
\hline 1403 & 0.129 & 371.809 & 8.5940 & 0.65399 & 0.109810 .001 & 368.273 & $0.689 \times 10^{-7} 0.004$ & 186.4 \\
\hline 1404 & 0.129 & 371.503 & 8.5973 & 0.59648 & $0.10998 \quad 0.001$ & 368.297 & $0.694 \times 10^{-7} 0.005$ & 185.3 \\
\hline 1405 & 0.129 & 371.206 & 8.6006 & 0.54161 & $0.11008 \quad 0.001$ & 368.308 & $0.695 \times 10^{-7} 0.006$ & 185.0 \\
\hline 1406 & 0.129 & 370.932 & 8.6036 & 0.48963 & 0.110100 .001 & 368.298 & $0.689 \times 10^{-7} 0.006$ & 186.3 \\
\hline 1407 & 0.129 & 370.634 & 8.6068 & 0.43960 & 0.110060 .001 & 368.382 & $0.685 \times 10^{-7} 0.008$ & 187.4 \\
\hline 1408 & 0.129 & 370.375 & 8.6097 & 0.39278 & 0.110090 .001 & 368.395 & $0.675 \times 10^{-7} 0.009$ & 190.0 \\
\hline 1501 & 0.391 & 405.204 & 8.2181 & 0.71525 & 0.101920 .000 & 401.334 & $0.646 \times 10^{-7} 0.004$ & 193.4 \\
\hline 1502 & 0.402 & 404.847 & 8.2225 & 0.65718 & 0.101810 .001 & 401.354 & $0.632 \times 10^{-7} 0.005$ & 197.2 \\
\hline 1503 & 0.410 & 404.522 & 8.2265 & 0.60151 & 0.102130 .000 & 401.323 & $0.648 \times 10^{-7} 0.004$ & 192.6 \\
\hline 1504 & 0.415 & 404.211 & 8.2302 & 0.54869 & 0.102130 .001 & 401.382 & $0.640 \times 10^{-7} 0.006$ & 194.9 \\
\hline 1505 & 0.425 & 403.927 & 8.2338 & 0.49827 & 0.102360 .001 & 401.345 & $0.650 \times 10^{-7} 0.006$ & 192.2 \\
\hline 1506 & 0.433 & 403.654 & 8.2371 & 0.45015 & 0.102270 .001 & 401.301 & $0.647 \times 10^{-7} 0.006$ & 192.8 \\
\hline 1507 & 0.439 & 403.391 & 8.2403 & 0.40460 & 0.102470 .001 & 401.345 & $0.658 \times 10^{-7} 0.007$ & 189.6 \\
\hline 1508 & 0.446 & 405.536 & 8.2152 & 0.77476 & 0.101970 .000 & 401.315 & $0.651 \times 10^{-7} 0.003$ & 192.0 \\
\hline 1601 & 0.554 & 426.783 & 7.9589 & 0.81341 & 0.097620 .000 & 422.459 & $0.621 \times 10^{-7} 0.003$ & 199.3 \\
\hline 1602 & 0.558 & 426.430 & 7.9634 & 0.75186 & 0.097350 .000 & 422.522 & $0.608 \times 10^{-7} 0.003$ & 202.5 \\
\hline 1603 & 0.561 & 426.075 & 7.9679 & 0.69337 & 0.097520 .000 & 422.539 & $0.616 \times 10^{-7} 0.003$ & 199.9 \\
\hline 1604 & 0.561 & 425.732 & 7.9722 & 0.63755 & 0.097610 .000 & 422.454 & $0.612 \times 10^{-7} 0.004$ & 201.3 \\
\hline 1605 & 0.562 & 425.405 & 7.9763 & 0.58387 & 0.097580 .000 & 422.551 & $0.610 \times 10^{-7} 0.004$ & 201.7 \\
\hline 1606 & 0.564 & 425.096 & 7.9802 & 0.53246 & 0.097630 .001 & 422.582 & $0.606 \times 10^{-7} 0.005$ & 202.9 \\
\hline 1607 & 0.566 & 424.796 & 7.9840 & 0.48350 & 0.097910 .001 & 422.497 & $0.618 \times 10^{-7} 0.005$ & 199.3 \\
\hline 1608 & 0.569 & 424.523 & 7.9875 & 0.43695 & 0.098020 .001 & 422.474 & $0.620 \times 10^{-7} 0.006$ & 198.9 \\
\hline 1701 & 0.768 & 453.898 & 7.6094 & 0.86040 & 0.092060 .000 & 449.481 & $0.584 \times 10^{-7} 0.003$ & 209.1 \\
\hline 1702 & 0.770 & 453.514 & 7.6147 & 0.80056 & 0.092150 .000 & 449.510 & $0.586 \times 10^{-7} 0.003$ & 208.5 \\
\hline 1703 & 0.772 & 453.140 & 7.6199 & 0.74281 & 0.092210 .000 & 449.496 & $0.589 \times 10^{-7} 0.003$ & 207.2 \\
\hline 1704 & 0.776 & 452.793 & 7.6247 & 0.68722 & 0.092220 .000 & 449.568 & $0.586 \times 10^{-7} 0.004$ & 207.9 \\
\hline 1705 & 0.779 & 452.439 & 7.6297 & 0.63370 & 0.092410 .000 & 449.538 & $0.589 \times 10^{-7} 0.003$ & 207.2 \\
\hline 1706 & 0.781 & 452.119 & 7.6341 & 0.58236 & 0.092240 .001 & 449.544 & $0.583 \times 10^{-7} 0.005$ & 208.6 \\
\hline 1707 & 0.782 & 451.799 & 7.6385 & 0.53352 & 0.092430 .001 & 449.527 & $0.586 \times 10^{-7} 0.005$ & 207.6 \\
\hline 1708 & 0.782 & 451.521 & 7.6423 & 0.48659 & 0.092440 .001 & 449.507 & $0.584 \times 10^{-7} 0.006$ & 208.2 \\
\hline
\end{tabular}


Table 1. Thermal conductivity, thermal diffusivity, and heat capacity of liquid toluene from 300 to $550 \mathrm{~K}-$ Continued

\begin{tabular}{|c|c|c|c|c|c|c|c|c|}
\hline Run Pt. & $\begin{array}{c}\text { Pressure } \\
\mathrm{MPa}\end{array}$ & $\begin{array}{l}\text { Temperature } \\
\text { K }\end{array}$ & $\begin{array}{c}\text { Density } \\
\mathrm{mol} / \mathrm{L}\end{array}$ & $\begin{array}{l}\text { Power } \\
\mathrm{W} / \mathrm{m}\end{array}$ & $\begin{array}{l}\text { Thermal } \\
\text { conductivity } \\
\text { W/(m:K) STAT }\end{array}$ & $\begin{array}{c}\text { Cell } \\
\text { temperature } \\
\mathrm{K}\end{array}$ & $\begin{array}{c}\text { Thermal } \\
\text { diffusivity } \\
\text { m²/s DSTAT }^{2}\end{array}$ & $\begin{array}{c}\text { Specific } \\
\text { heat } \\
J /(\mathrm{mol} \cdot \mathrm{K})\end{array}$ \\
\hline 1801 & 1.023 & 480.654 & 7.2293 & 0.84664 & 0.087200 .000 & 473.650 & $0.560 \times 10^{-7} 0.003$ & 217.4 \\
\hline 1802 & 1.018 & 480.279 & 7.2349 & 0.78957 & 0.087090 .000 & 473.684 & $0.561 \times 10^{-7} 0.003$ & 216.6 \\
\hline 1803 & 1.016 & 479.914 & 7.2405 & 0.73476 & 0.087280 .000 & 473.684 & $0.565 \times 10^{-7} 0.004$ & 215.2 \\
\hline 1804 & 1.014 & 479.555 & 7.2459 & 0.68157 & 0.087380 .000 & 473.713 & $0.568 \times 10^{-7} 0.003$ & 213.9 \\
\hline 1805 & 1.014 & 479.212 & 7.2512 & 0.63048 & 0.087390 .000 & 473.808 & $0.568 \times 10^{-7} 0.004$ & 213.7 \\
\hline 1806 & 1.009 & 478.875 & 7.2562 & 0.58183 & $0.08742 \quad 0.001$ & 473.789 & $0.559 \times 10^{-7} 0.004$ & 217.0 \\
\hline 1807 & 1.008 & 478.564 & 7.2609 & 0.53447 & 0.087540 .001 & 473.801 & $0.569 \times 10^{-7} 0.005$ & 213.1 \\
\hline 1808 & 1.008 & 478.262 & 7.2655 & 0.48937 & 0.087640 .001 & 473.753 & $0.564 \times 10^{-7} 0.005$ & 215.3 \\
\hline 1901 & 1.681 & 504.349 & 6.8718 & 0.88755 & 0.083370 .000 & 497.373 & $0.554 \times 10^{-7} 0.003$ & 221.5 \\
\hline 1902 & 1.673 & 503.948 & 6.8784 & 0.82922 & 0.083380 .000 & 497.373 & $0.560 \times 10^{-7} 0.003$ & 218.8 \\
\hline 1903 & 1.669 & 503.572 & 6.8847 & 0.77381 & 0.083520 .000 & 497.404 & $0.566 \times 10^{-7} 0.003$ & 216.3 \\
\hline 1904 & 1.662 & 503.194 & 6.8909 & 0.71986 & 0.083470 .000 & 497.340 & $0.565 \times 10^{-7} 0.003$ & 216.4 \\
\hline 1905 & 1.659 & 502.816 & 6.8973 & 0.66827 & 0.083560 .000 & 497.278 & $0.551 \times 10^{-7} 0.003$ & 221.6 \\
\hline 1906 & 1.654 & 502.464 & 6.9031 & 0.61856 & 0.083660 .000 & 497.298 & $0.554 \times 10^{-7} 0.004$ & 220.4 \\
\hline 1907 & 1.651 & 502.127 & 6.9088 & 0.57068 & 0.083750 .001 & 497.277 & $0.553 \times 10^{-7} 0.004$ & 220.8 \\
\hline 1908 & 1.647 & 501.825 & 6.9138 & 0.52450 & $0.08380 \quad 0.001$ & 497.309 & $0.558 \times 10^{-7} 0.005$ & 218.5 \\
\hline 2001 & 2.293 & 526.378 & 6.4964 & 0.87427 & 0.080460 .000 & 519.727 & $0.542 \times 10^{-7} 0.003$ & 230.8 \\
\hline 2002 & 2.295 & 525.971 & 6.5049 & 0.81718 & 0.080460 .000 & 519.611 & $0.542 \times 10^{-7} 0.003$ & 230.5 \\
\hline 2003 & 2.297 & 525.577 & 6.5132 & 0.76206 & 0.080630 .000 & 519.568 & $0.549 \times 10^{-7} 0.003$ & 227.8 \\
\hline 2004 & 2.299 & 525.193 & 6.5212 & 0.70904 & 0.080590 .000 & 519.685 & $0.547 \times 10^{-7} 0.004$ & 228.1 \\
\hline 2005 & 2.301 & 524.830 & 6.5287 & 0.65793 & 0.080790 .000 & 519.738 & $0.547 \times 10^{-7} 0.004$ & 228.2 \\
\hline 2006 & 2.302 & 524.479 & 6.5359 & 0.60865 & $0.08078 \quad 0.000$ & 519.685 & $0.545 \times 10^{-7} 0.004$ & 228.5 \\
\hline 2007 & 2.305 & 524.144 & 6.5429 & 0.56137 & 0.080890 .001 & 519.685 & $0.550 \times 10^{-7} 0.004$ & 226.4 \\
\hline 2008 & 2.306 & 523.830 & 6.5493 & 0.51601 & $0.08103 \quad 0.001$ & 519.706 & $0.558 \times 10^{-7} 0.006$ & 223.1 \\
\hline 2101 & 2.682 & 554.337 & 5.8477 & 0.86413 & 0.076530 .001 & 548.030 & $0.516 \times 10^{-7} 0.007$ & 254.8 \\
\hline 2102 & 2.683 & 553.911 & 5.8611 & 0.80784 & 0.076590 .001 & 548.130 & $0.517 \times 10^{-7} 0.007$ & 253.6 \\
\hline 2103 & 2.684 & 553.515 & 5.8736 & 0.75366 & 0.076720 .001 & 548.063 & $0.523 \times 10^{-7} 0.008$ & 250.8 \\
\hline 2104 & 2.686 & 553.111 & 5.8862 & 0.70126 & $\begin{array}{lll}0.07680 & 0.001\end{array}$ & 548.109 & $0.524 \times 10^{-7} 0.006$ & 250.2 \\
\hline 2105 & 2.686 & 552.722 & 5.8981 & 0.65069 & 0.076860 .001 & 548.140 & $0.522 \times 10^{-7} 0.009$ & 250.7 \\
\hline 2106 & 2.688 & 552.367 & 5.9089 & 0.60212 & $0.07703 \quad 0.001$ & 548.129 & $0.533 \times 10^{-7} 0.009$ & 245.6 \\
\hline 2107 & 2.688 & 552.041 & 5.9187 & 0.55544 & $0.07702 \quad 0.001$ & 548.132 & $0.532 \times 10^{-7} 0.010$ & 245.6 \\
\hline 2108 & 2.691 & 551.695 & 5.9294 & 0.51041 & 0.077090 .001 & 548.141 & $0.534 \times 10^{-7} 0.011$ & 244.1 \\
\hline 2109 & 19.346 & 553.364 & 6.9566 & 0.86455 & $0.09108 \quad 0.000$ & 548.247 & $0.632 \times 10^{-7} 0.003$ & 211.7 \\
\hline 2110 & 19.353 & 552.979 & 6.9613 & 0.80814 & 0.091190 .000 & 548.194 & $0.633 \times 10^{-7} 0.004$ & 211.2 \\
\hline 2111 & 19.357 & 552.629 & 6.9654 & 0.75383 & 0.091200 .000 & 548.217 & $0.631 \times 10^{-7} 0.004$ & 211.5 \\
\hline 2112 & 19.358 & 552.276 & 6.9695 & 0.70146 & 0.091070 .001 & 548.226 & $0.619 \times 10^{-7} 0.004$ & 214.9 \\
\hline 2113 & 14.335 & 553.521 & 6.7600 & 0.86425 & 0.087740 .000 & 548.096 & $0.607 \times 10^{-7} 0.003$ & 218.3 \\
\hline 2114 & 14.335 & 553.155 & 6.7648 & 0.80806 & 0.087750 .000 & 548.075 & $0.608 \times 10^{-7} 0.003$ & 217.4 \\
\hline 2115 & 14.335 & 552.794 & 6.7695 & 0.75378 & 0.087890 .001 & 548.132 & $0.613 \times 10^{-7} 0.004$ & 215.5 \\
\hline 2116 & 14.336 & 552.424 & 6.7744 & 0.70141 & $\begin{array}{lll}0.08778 & 0.001\end{array}$ & 548.153 & $0.603 \times 10^{-7} 0.005$ & 218.6 \\
\hline 2117 & 9.599 & 553.745 & 6.5167 & 0.86414 & 0.084080 .000 & 548.099 & $0.586 \times 10^{-7} 0.004$ & 224.4 \\
\hline 2118 & 9.599 & 553.363 & 6.5227 & 0.80789 & 0.084180 .000 & 548.088 & $0.592 \times 10^{-7} 0.004$ & 221.9 \\
\hline 2119 & 9.599 & 553.003 & 6.5283 & 0.75370 & 0.084230 .001 & 548.045 & $0.598 \times 10^{-7} 0.004$ & 219.2 \\
\hline 2120 & 9.598 & 552.630 & 6.5341 & 0.70139 & 0.084200 .001 & 548.065 & $0.592 \times 10^{-7} 0.004$ & 221.1 \\
\hline 2121 & 6.941 & 553.927 & 6.3343 & 0.86406 & 0.081790 .000 & 548.065 & $0.579 \times 10^{-7} 0.004$ & 226.7 \\
\hline 2122 & 6.941 & 553.531 & 6.3415 & 0.80788 & 0.081920 .000 & 548.078 & $0.587 \times 10^{-7} 0.004$ & 223.6 \\
\hline 2123 & 6.941 & 553.133 & 6.3487 & 0.75367 & 0.082020 .001 & 548.045 & $0.589 \times 10^{-7} 0.005$ & 222.4 \\
\hline 2124 & 6.942 & 552.777 & 6.3552 & 0.70128 & 0.081990 .001 & 548.065 & $0.588 \times 10^{-7} 0.005$ & 222.5 \\
\hline 2125 & 4.512 & 554.119 & 6.1081 & 0.86378 & 0.078850 .000 & 548.033 & $0.550 \times 10^{-7} 0.004$ & 237.6 \\
\hline 2126 & 4.512 & 553.711 & 6.1173 & 0.80730 & $0.07890 \quad 0.001$ & 548.023 & $0.556 \times 10^{-7} 0.004$ & 234.7 \\
\hline 2127 & 4.512 & 553.323 & 6.1261 & 0.75307 & 0.079040 .000 & 548.033 & $0.567 \times 10^{-7} 0.004$ & 230.2 \\
\hline 2128 & 4.512 & 552.936 & 6.1348 & 0.70093 & $0.07910 \quad 0.001$ & 548.034 & $0.565 \times 10^{-7} 0.004$ & 230.4 \\
\hline
\end{tabular}


Table 2. Thermal conductivity, thermal diffusivity, and heat capacity of argon gas near $300 \mathrm{~K}$

\begin{tabular}{|c|c|c|c|c|c|c|c|c|}
\hline Run Pt. & $\begin{array}{l}\text { Prcssure } \\
\mathrm{MPa}\end{array}$ & $\begin{array}{c}\text { Temperature } \\
\mathbf{K}\end{array}$ & $\begin{array}{c}\text { Density } \\
\mathrm{mol} / \mathrm{L}\end{array}$ & $\begin{array}{l}\text { Power } \\
W / m\end{array}$ & $\begin{array}{l}\text { Thermal } \\
\text { conductivity } \\
\text { W/(m/K) STAT }\end{array}$ & $\begin{array}{c}\text { Cell } \\
\text { temperature } \\
\mathbf{K}\end{array}$ & $\begin{array}{c}\text { Thermal } \\
\text { diffusivity } \\
\mathrm{m}^{2} / \mathrm{s} \text { DSTAT }\end{array}$ & $\begin{array}{c}\text { Specific } \\
\text { heat } \\
\mathrm{J} /(\mathrm{mol} \cdot \mathrm{K})\end{array}$ \\
\hline 1001 & 65.224 & 301.925 & 19.9271 & 0.33737 & 0.053780 .000 & 298.178 & $0.795 \times 10^{-7} 0.004$ & 33.9 \\
\hline 1002 & 65.224 & 301.453 & 19.9550 & 0.29703 & 0.053810 .000 & 298.145 & $0.772 \times 10^{-7} 0.004$ & 34.9 \\
\hline 1003 & 65.224 & 301.021 & 19.9805 & 0.25949 & 0.053920 .001 & 298.188 & $0.768 \times 10^{-7} 0.005$ & 35.1 \\
\hline 1004 & 65.223 & 300.621 & 20.0041 & 0.22432 & $0.05404 \quad 0.001$ & 298.152 & $0.767 \times 10^{-7} 0.006$ & 35.2 \\
\hline 1005 & 60.534 & 301.982 & 19.1757 & 0.33733 & 0.051280 .000 & 298.079 & $0.772 \times 10^{-7} 0.004$ & 34.6 \\
\hline 1006 & 60.533 & 301.554 & 19.2011 & 0.29699 & 0.051310 .001 & 298.069 & $0.774 \times 10^{-7} 0.005$ & 34.5 \\
\hline 1007 & 60.533 & 301.101 & 19.2281 & 0.25926 & 0.051360 .001 & 298.067 & $0.771 \times 10^{-7} 0.005$ & 34.6 \\
\hline 1008 & 60.531 & 300.698 & 19.2520 & 0.22406 & 0.051410 .001 & 298.105 & $0.768 \times 10^{-7} 0.006$ & 34.7 \\
\hline 1009 & 56.254 & 301.663 & 18.4516 & 0.29684 & 0.048990 .000 & 298.073 & $0.753 \times 10^{-7} 0.004$ & 35.1 \\
\hline 1010 & 56.254 & 301.195 & 18.4801 & 0.25917 & 0.049050 .001 & 298.029 & $0.758 \times 10^{-7} 0.005$ & 34.9 \\
\hline 1011 & 56.254 & 300.770 & 18.5058 & 0.22406 & 0.049070 .001 & 298.081 & $0.753 \times 10^{-7} 0.006$ & 35.1 \\
\hline 1012 & 56.256 & 300.350 & 18.5315 & 0.19174 & 0.049250 .001 & 298.081 & $0.757 \times 10^{-7} 0.007$ & 35.1 \\
\hline 1013 & 52.289 & 301.803 & 17.6955 & 0.29714 & 0.046830 .001 & 298.017 & $0.750 \times 10^{-7} 0.004$ & 35.2 \\
\hline 1014 & 52.289 & 301.333 & 17.7241 & 0.25931 & 0.046870 .001 & 298.049 & $0.755 \times 10^{-7} 0.005$ & 34.9 \\
\hline 1015 & 52.289 & 300.877 & 17.7519 & 0.22425 & 0.046960 .001 & 298.047 & $0.750 \times 10^{-7} 0.006$ & 35.2 \\
\hline 1016 & 52.288 & 300.462 & 17.7771 & 0.19162 & 0.047020 .001 & 298.051 & $0.746 \times 10^{-7} 0.007$ & 35.4 \\
\hline 1017 & 48.788 & 301.940 & 16.9726 & 0.29698 & 0.044860 .000 & 298.026 & $0.749 \times 10^{-7} 0.004$ & 35.1 \\
\hline 1018 & 48.789 & 301.451 & 17.0025 & 0.25927 & 0.044920 .001 & 298.000 & $0.752 \times 10^{-7} 0.004$ & 35.0 \\
\hline 1019 & 48.789 & 300.978 & 17.0314 & 0.22414 & 0.044960 .001 & 298.019 & $0.749 \times 10^{-7} 0.005$ & 35.1 \\
\hline 1020 & 48.788 & 300.553 & 17.0573 & 0.19154 & 0.045040 .001 & 298.031 & $0.751 \times 10^{-7} 0.007$ & 35.0 \\
\hline 1021 & 45.435 & 302.110 & 16.2241 & 0.29672 & 0.043060 .000 & 298.010 & $0.769 \times 10^{-7} \quad 0.003$ & 34.3 \\
\hline 1022 & 45.435 & 301.595 & 16.2553 & 0.25911 & 0.043040 .001 & 297.992 & $0.763 \times 10^{-7} 0.004$ & 34.5 \\
\hline 1023 & 45.435 & 301.120 & 16.2842 & 0.22393 & 0.043020 .001 & 298.020 & $0.762 \times 10^{-7} 0.005$ & 34.5 \\
\hline 1024 & 45.435 & 300.652 & 16.3128 & 0.19141 & 0.043080 .001 & 297.990 & $0.765 \times 10^{-7} 0.006$ & 34.4 \\
\hline 1025 & 42.251 & 301.754 & 15.4902 & 0.25937 & 0.041170 .001 & 298.003 & $0.749 \times 10^{-7} 0.005$ & 35.2 \\
\hline 1026 & 42.251 & 301.239 & 15.5212 & 0.22413 & 0.041190 .001 & 297.997 & $0.742 \times 10^{-7} \quad 0.005$ & 35.5 \\
\hline 1027 & 42.249 & 300.762 & 15.5498 & 0.19151 & 0.041270 .001 & 298.024 & $0.736 \times 10^{-7} 0.006$ & 35.9 \\
\hline 1028 & 42.249 & 300.317 & 15.5767 & 0.16149 & 0.041310 .001 & 297.949 & $0.727 \times 10^{-7} 0.008$ & 36.4 \\
\hline 1029 & 39.526 & 301.865 & 14.7903 & 0.25936 & 0.039550 .000 & 298.007 & $0.749 \times 10^{-7} 0.004$ & 35.4 \\
\hline 1030 & 39.526 & 301.334 & 14.8219 & 0.22432 & 0.039590 .001 & 297.965 & $0.751 \times 10^{-7} 0.005$ & 35.3 \\
\hline 1031 & 39.526 & 300.853 & 14.8508 & 0.19179 & 0.039650 .001 & 297.975 & $0.751 \times 10^{-7} 0.006$ & 35.3 \\
\hline 1032 & 39.525 & 300.389 & 14.8785 & 0.16183 & 0.039750 .001 & 298.012 & $0.748 \times 10^{-7} 0.008$ & 35.5 \\
\hline 1033 & 36.708 & 302.037 & 14.0145 & 0.25981 & $0.03800 \quad 0.000$ & 298.005 & $0.774 \times 10^{-7} 0.004$ & 34.7 \\
\hline 1034 & 36.708 & 301.493 & 14.0464 & 0.22461 & 0.037910 .001 & 298.010 & $0.762 \times 10^{-7} 0.005$ & 35.1 \\
\hline 1035 & 36.710 & 300.960 & 14.0781 & 0.19185 & 0.037940 .001 & 298.041 & $0.759 \times 10^{-7} 0.005$ & 35.3 \\
\hline 1036 & 36.710 & 300.488 & 14.1059 & 0.16175 & 0.037980 .001 & 298.019 & $0.756 \times 10^{-7} 0.007$ & 35.4 \\
\hline 1037 & 33.968 & 302.077 & 13.2166 & 0.25240 & 0.036220 .001 & 297.990 & $0.773 \times 10^{-7} 0.005$ & 35.0 \\
\hline 1038 & 33.968 & 301.609 & 13.2432 & 0.22419 & 0.036270 .001 & 297.950 & $0.777 \times 10^{-7} 0.005$ & 34.9 \\
\hline 1039 & 33.969 & 301.175 & 13.2683 & 0.19786 & 0.036260 .001 & 297.929 & $0.779 \times 10^{-7} 0.005$ & 34.8 \\
\hline 1040 & 33.969 & 300.784 & 13.2907 & 0.17318 & 0.036270 .001 & 297.930 & $0.773 \times 10^{-7} 0.007$ & 35.1 \\
\hline 1041 & 31.748 & 302.007 & 12.5367 & 0.23797 & 0.034910 .000 & 297.938 & $0.806 \times 10^{-7} 0.004$ & 34.1 \\
\hline 1042 & 31.748 & 301.535 & 12.5629 & 0.21097 & 0.034890 .001 & 297.946 & $0.795 \times 10^{-7} 0.005$ & 34.6 \\
\hline 1043 & 31.748 & 301.096 & 12.5873 & 0.18554 & 0.034920 .001 & 297.926 & $0.795 \times 10^{-7} 0.006$ & 34.6 \\
\hline 1044 & 31.749 & 300.678 & 12.6109 & 0.16143 & 0.034970 .001 & 297.941 & $0.796 \times 10^{-7} 0.007$ & 34.5 \\
\hline 1045 & 29.280 & 301.947 & 11.7377 & 0.22396 & 0.033470 .000 & 297.936 & $0.839 \times 10^{-7} 0.004$ & 33.6 \\
\hline 1046 & 29.281 & 301.476 & 11.7630 & 0.19797 & 0.033530 .001 & 297.935 & $0.849 \times 10^{-7} 0.005$ & 33.2 \\
\hline 1047 & 29.281 & 301.044 & 11.7859 & 0.17332 & 0.033550 .001 & 297.909 & $0.840 \times 10^{-7} 0.006$ & 33.5 \\
\hline 1048 & 29.282 & 300.612 & 11.8092 & 0.15021 & 0.033470 .001 & 297.956 & $0.826 \times 10^{-7} 0.007$ & 34.0 \\
\hline 1049 & 27.318 & 301.897 & 11.0699 & 0.21088 & 0.032160 .000 & 297.971 & $0.836 \times 10^{-7} 0.004$ & 34.3 \\
\hline 1050 & 27.319 & 301.427 & 11.0940 & 0.18535 & 0.032120 .001 & 297.945 & $0.830 \times 10^{-7} 0.005$ & 34.5 \\
\hline 1051 & 27.319 & 300.963 & 11.1178 & 0.16128 & 0.032170 .001 & 297.930 & $0.832 \times 10^{-7} 0.006$ & 34.4 \\
\hline 1052 & 27.320 & 300.558 & 11.1389 & 0.13912 & 0.032250 .001 & 297.957 & $0.836 \times 10^{-7} 0.008$ & 34.3 \\
\hline 1053 & 25.276 & 302.085 & 10.3335 & 0.21027 & 0.030910 .001 & 297.951 & $0.890 \times 10^{-7} 0.004$ & 33.1 \\
\hline
\end{tabular}


Table 2. Thcrmal conductivity, thermal diffusivity, and heat capacity of argon gas near $300 \mathrm{~K}$-Continued

\begin{tabular}{|c|c|c|c|c|c|c|c|c|}
\hline Run Pt. & $\begin{array}{l}\text { Pressure } \\
\text { MPa }\end{array}$ & $\begin{array}{l}\text { Temperature } \\
\mathbf{K}\end{array}$ & $\begin{array}{l}\text { Density } \\
\mathrm{mol} / \mathrm{L}\end{array}$ & $\begin{array}{l}\text { Power } \\
\text { W/m }\end{array}$ & $\begin{array}{l}\text { Thermal } \\
\text { conductivity } \\
\text { W/(m·K) STAT }\end{array}$ & $\begin{array}{c}\text { Cell } \\
\text { temperature } \\
\mathbf{K}\end{array}$ & $\begin{array}{c}\text { Thermal } \\
\text { diffusivity } \\
\mathrm{m}^{2} / \mathrm{s} \text { DSTAT }\end{array}$ & $\begin{array}{c}\text { Specific } \\
\text { heat } \\
J /(\text { mol } \cdot \mathrm{K})\end{array}$ \\
\hline 1054 & 25.276 & 301.603 & 10.3566 & 0.18491 & 0.030920 .001 & 297.979 & $0.884 \times 10^{-7} 0.005$ & 33.3 \\
\hline 1055 & 25.276 & 301.123 & 10.3796 & 0.16112 & 0.030890 .001 & 297.932 & $0.879 \times 10^{-7} 0.006$ & 33.4 \\
\hline 1056 & 25.276 & 300.690 & 10.4005 & 0.13915 & 0.030960 .001 & 297.956 & $0.881 \times 10^{-7} 0.007$ & 33.4 \\
\hline 1057 & 23.207 & 302.038 & 9.5687 & 0.19758 & 0.029660 .000 & 298.009 & $0.928 \times 10^{-7} 0.004$ & 32.8 \\
\hline 1058 & 23.207 & 301.529 & 9.5916 & 0.17297 & 0.029690 .001 & 297.980 & $0.936 \times 10^{-7} 0.005$ & 32.6 \\
\hline 1059 & 23.208 & 301.072 & 9.6124 & 0.14995 & $0.02968 \quad 0.001$ & 298.006 & $0.933 \times 10^{-7} 0.006$ & 32.7 \\
\hline 1060 & 23.208 & 300.634 & 9.6321 & 0.12854 & 0.029670 .001 & 298.007 & $0.926 \times 10^{-7} 0.008$ & 32.9 \\
\hline 1061 & 21.499 & 301.961 & 8.9175 & 0.18527 & 0.028680 .001 & 297.969 & $0.100 \times 10^{-6} 0.005$ & 31.4 \\
\hline 1062 & 21.499 & 301.451 & 8.9387 & 0.16130 & 0.028620 .001 & 297.983 & $0.991 \times 10^{-7} 0.006$ & 31.8 \\
\hline 1063 & 21.499 & 301.206 & 8.9490 & 0.14993 & 0.028640 .001 & 297.953 & $0.998 \times 10^{-7} 0.006$ & 31.6 \\
\hline 1064 & 21.499 & 300.536 & 8.9771 & 0.11843 & 0.028670 .001 & 297.978 & $0.100 \times 10^{-6} 0.009$ & 31.5 \\
\hline 1065 & 19.660 & 301.868 & 8.1962 & 0.17302 & 0.027530 .001 & 297.975 & $0.101 \times 10^{-6} 0.005$ & 32.6 \\
\hline 1066 & 19.660 & 301.342 & 8.2163 & 0.14986 & 0.027530 .001 & 297.986 & $0.100 \times 10^{-6} 0.006$ & 32.9 \\
\hline 1067 & 19.660 & 300.856 & 8.2350 & 0.12845 & 0.027530 .001 & 297.981 & $0.989 \times 10^{-7} 0.008$ & 33.4 \\
\hline 1068 & 19.662 & 300.399 & 8.2532 & 0.10874 & 0.027560 .001 & 298.003 & $0.976 \times 10^{-7} 0.009$ & 33.8 \\
\hline 1069 & 17.864 & 302.035 & 7.4644 & 0.17310 & 0.026430 .001 & 298.005 & $0.111 \times 10^{-6} 0.006$ & 31.4 \\
\hline 1070 & 17.864 & 301.489 & 7.4833 & 0.15007 & 0.026420 .001 & 297.966 & $0.109 \times 10^{-6} 0.006$ & 31.7 \\
\hline 1071 & 17.864 & 300.981 & 7.5010 & 0.12874 & $0.02644 \quad 0.001$ & 297.933 & $0.109 \times 10^{-6} 0.007$ & 32.0 \\
\hline 1072 & 17.864 & 300.516 & 7.5173 & 0.10900 & 0.026470 .001 & 297.960 & $0.108 \times 10^{-6} 0.010$ & 32.3 \\
\hline 1073 & 16.141 & 302.241 & 6.7481 & 0.17324 & 0.025450 .001 & 297.971 & $0.121 \times 10^{-6} 0.005$ & 30.5 \\
\hline 1074 & 16.141 & 301.664 & 6.7659 & 0.15023 & 0.025420 .001 & 297.956 & $0.119 \times 10^{-6} 0.006$ & 30.9 \\
\hline 1075 & 16.141 & 301.119 & 6.7828 & 0.12876 & 0.025440 .001 & 297.989 & $0.120 \times 10^{-6} 0.007$ & 30.8 \\
\hline 1076 & 16.141 & 300.607 & 6.7988 & 0.10905 & 0.025460 .001 & 297.956 & $0.119 \times 10^{-6} 0.009$ & 31.0 \\
\hline 1077 & 14.442 & 302.139 & 6.0414 & 0.16149 & 0.024460 .001 & 297.970 & $0.133 \times 10^{-6} 0.005$ & 29.7 \\
\hline 1078 & 14.442 & 301.576 & 6.0568 & 0.13912 & 0.024450 .001 & 297.955 & $0.133 \times 10^{-6} 0.006$ & 29.7 \\
\hline 1079 & 14.442 & 301.049 & 6.0712 & 0.11858 & 0.024420 .001 & 297.977 & $0.132 \times 10^{-6} 0.007$ & 30.1 \\
\hline 1080 & 14.442 & 300.563 & 6.0846 & 0.09963 & 0.024460 .001 & 297.960 & $0.132 \times 10^{-6} 0.010$ & 30.1 \\
\hline 1081 & 12.754 & 302.079 & 5.3298 & 0.14979 & 0.023510 .001 & 297.927 & $0.151 \times 10^{-6} 0.006$ & 28.6 \\
\hline 1082 & 12.754 & 301.496 & 5.3436 & 0.12843 & $0.02348 \quad 0.001$ & 297.950 & $0.149 \times 10^{-6} 0.006$ & 29.0 \\
\hline 1083 & 12.754 & 300.934 & 5.3569 & 0.10882 & 0.023520 .001 & 298.002 & $0.149 \times 10^{-6} 0.008$ & 29.0 \\
\hline 1084 & 12.754 & 300.446 & 5.3685 & 0.09075 & 0.023490 .001 & 298.003 & $0.148 \times 10^{-6} 0.011$ & 29.2 \\
\hline 1085 & 10.898 & 302.004 & 4.5421 & 0.13917 & 0.022530 .001 & 297.935 & $0.172 \times 10^{-6} 0.006$ & 28.1 \\
\hline 1086 & 10.898 & 301.417 & 4.5539 & 0.11851 & 0.022510 .001 & 297.945 & $0.171 \times 10^{-6} 0.007$ & 28.4 \\
\hline 1087 & 10.898 & 300.864 & 4.5648 & 0.09964 & 0.022510 .001 & 297.996 & $0.169 \times 10^{-6} 0.009$ & 28.7 \\
\hline 1088 & 10.898 & 300.355 & 4.5748 & 0.08236 & 0.022510 .001 & 297.951 & $0.166 \times 10^{-6} 0.012$ & 29.3 \\
\hline 1089 & 9.295 & 302.244 & 3.8552 & 0.13887 & 0.021710 .001 & 297.960 & $0.205 \times 10^{-6} 0.006$ & 26.8 \\
\hline 1090 & 9.295 & 301.611 & 3.8654 & 0.11841 & 0.021670 .001 & 297.949 & $0.202 \times 10^{-6} 0.007$ & 27.2 \\
\hline 1091 & 9.295 & 301.033 & 3.8748 & 0.09956 & 0.021660 .001 & 297.938 & $0.200 \times 10^{-6} 0.009$ & 27.5 \\
\hline 1092 & 9.294 & 300.501 & 3.8832 & 0.08235 & $0.02169 \quad 0.001$ & 297.979 & $0.199 \times 10^{-6} 0.012$ & 27.7 \\
\hline 1093 & 7.510 & 302.191 & 3.0984 & 0.12862 & 0.020850 .001 & 297.991 & $0.247 \times 10^{-6} 0.006$ & 26.5 \\
\hline 1093 & 7.510 & 301.544 & 3.1064 & 0.10882 & $0.02082 \quad 0.001$ & 297.941 & $0.243 \times 10^{-6} 0.008$ & 27.0 \\
\hline 1095 & 7.510 & 300.939 & 3.1138 & 0.09061 & 0.020830 .001 & 297.995 & $0.245 \times 10^{-6} 0.010$ & 26.8 \\
\hline 1096 & 7.509 & 300.403 & 3.1203 & 0.07423 & 0.020840 .001 & 297.975 & $0.244 \times 10^{-6} 0.014$ & 27.0 \\
\hline 1097 & 5.829 & 302.136 & 2.3897 & 0.11818 & $0.02008 \quad 0.001$ & 297.999 & $0.324 \times 10^{-6} 0.007$ & 25.2 \\
\hline 1098 & 5.828 & 301.479 & 2.3955 & 0.09942 & $0.02008 \quad 0.001$ & 297.970 & $0.324 \times 10^{-6} 0.009$ & 25.3 \\
\hline 1099 & 5.827 & 300.879 & 2.4009 & 0.08221 & 0.020040 .001 & 297.970 & $0.319 \times 10^{-6} 0.012$ & 25.7 \\
\hline 1100 & 5.827 & 300.298 & 2.4060 & 0.06671 & 0.020090 .002 & 297.950 & $0.307 \times 10^{-6} 0.015$ & 26.8 \\
\hline 1101 & 4.375 & 302.061 & 1.7826 & 0.10864 & $0.01960 \quad 0.001$ & 297.985 & $0.429 \times 10^{-6} 0.008$ & 25.0 \\
\hline 1102 & 4.375 & 301.373 & 1.7872 & 0.09059 & 0.019520 .001 & 297.980 & $0.413 \times 10^{-6} 0.011$ & 25.9 \\
\hline 1103 & 4.375 & 300.743 & 1.7915 & 0.07418 & 0.019510 .001 & 297.997 & $0.403 \times 10^{-6} 0.014$ & 26.5 \\
\hline 1104 & 4.375 & 300.195 & 1.7952 & 0.05939 & $0.01948 \quad 0.002$ & 298.010 & $0.388 \times 10^{-6} 0.019$ & 27.6 \\
\hline 1105 & 2.601 & 302.360 & 1.0495 & 0.10871 & 0.018930 .001 & 297.970 & $0.693 \times 10^{-6} 0.010$ & 25.3 \\
\hline 1106 & 2.601 & 301.634 & 1.0522 & 0.09071 & 0.018870 .001 & 297.950 & $0.676 \times 10^{-6} 0.011$ & 25.9 \\
\hline
\end{tabular}


Table 2. Thermal conductivity, thermal diffusivity, and heat capacity of argon gas near $300 \mathrm{~K}-$ Continued

\begin{tabular}{|c|c|c|c|c|c|c|c|c|}
\hline Run Pt. & $\begin{array}{l}\text { Pressure } \\
\mathrm{MPa}\end{array}$ & $\begin{array}{c}\text { Temperature } \\
\mathbf{K}\end{array}$ & $\begin{array}{l}\text { Density } \\
\text { mol/L }\end{array}$ & $\begin{array}{l}\text { Power } \\
\text { W/m }\end{array}$ & $\begin{array}{c}\text { Thermal } \\
\text { conductivity } \\
\text { W/(m/K) STAT }\end{array}$ & $\begin{array}{c}\text { Cell } \\
\text { temperature } \\
\mathbf{K}\end{array}$ & $\begin{array}{c}\text { Thermal } \\
\text { diffusivity } \\
\mathrm{m}^{2} / \mathrm{s} \text { DSTAT }\end{array}$ & $\begin{array}{c}\text { Specific } \\
\text { heat } \\
J /(\mathrm{mol} \cdot \mathrm{K})\end{array}$ \\
\hline 1107 & 2.600 & 300.980 & 1.0544 & 0.07435 & 0.018860 .001 & 297.999 & $0.655 \times 10^{-6} 0.014$ & 26.8 \\
\hline 1108 & 2.600 & 300.356 & 1.0567 & 0.05952 & $0.01885 \quad 0.002$ & 297.976 & $0.631 \times 10^{-6} 0.018$ & 27.9 \\
\hline 1109 & 65.509 & 302.887 & 19.9141 & 0.41761 & 0.053740 .000 & 298.353 & $0.761 \times 10^{-7} 0.004$ & 35.4 \\
\hline 1110 & 65.499 & 302.474 & 19.9368 & 0.38071 & 0.053780 .000 & 298.313 & $0.759 \times 10^{-7} 0.004$ & 35.4 \\
\hline 1111 & 65.484 & 302.092 & 19.9570 & 0.34638 & 0.053880 .000 & 298.261 & $0.778 \times 10^{-7} 0.004$ & 34.7 \\
\hline 1112 & 65.474 & 301.728 & 19.9769 & 0.31306 & 0.053870 .001 & 298.282 & $0.778 \times 10^{-7} 0.004$ & 34.6 \\
\hline 1113 & 65.468 & 301.382 & 19.9964 & 0.28165 & 0.053890 .001 & 298.266 & $0.780 \times 10^{-7} 0.005$ & 34.5 \\
\hline 1114 & 65.454 & 301.034 & 20.0147 & 0.25238 & 0.053960 .001 & 298.257 & $0.765 \times 10^{-7} 0.006$ & 35.2 \\
\hline 1115 & 65.447 & 300.704 & 20.0331 & 0.22404 & $0.05408 \quad 0.001$ & 298.216 & $0.767 \times 10^{-7} 0.007$ & 35.1 \\
\hline 1116 & 65.437 & 300.433 & 20.0478 & 0.19763 & 0.054050 .001 & 298.226 & $0.757 \times 10^{-7} 0.008$ & 35.6 \\
\hline 1117 & 65.430 & 300.168 & 20.0624 & 0.17284 & $0.05403 \quad 0.001$ & 298.269 & $0.780 \times 10^{-7} 0.009$ & 34.5 \\
\hline 1118 & 65.422 & 299.903 & 20.0769 & 0.14987 & 0.054070 .001 & 298.303 & $0.764 \times 10^{-7} 0.011$ & 35.2 \\
\hline 1119 & 65.414 & 299.654 & 20.0905 & 0.12847 & 0.054100 .002 & 298.231 & $0.748 \times 10^{-7} 0.014$ & 36.0 \\
\hline 1120 & 65.407 & 299.444 & 20.1018 & 0.10873 & 0.054130 .002 & 298.267 & $0.733 \times 10^{-7} 0.017$ & 36.7 \\
\hline 1121 & 65.353 & 299.421 & 20.0951 & 0.10852 & 0.054060 .002 & 298.212 & $0.756 \times 10^{-7} 0.016$ & 35.6 \\
\hline 1122 & 65.348 & 299.641 & 20.0812 & 0.12835 & 0.054050 .002 & 298.269 & $0.773 \times 10^{-7} 0.014$ & 34.8 \\
\hline 1123 & 65.338 & 299.869 & 20.0662 & 0.14973 & 0.054010 .001 & 298.227 & $0.766 \times 10^{-7} 0.011$ & 35.1 \\
\hline 1124 & 65.331 & 300.121 & 20.0501 & 0.17277 & 0.054050 .001 & 298.222 & $0.783 \times 10^{-7} 0.009$ & 34.4 \\
\hline 1125 & 65.322 & 300.404 & 20.0319 & 0.19739 & 0.053950 .001 & 298.222 & $0.780 \times 10^{-7} 0.008$ & 34.5 \\
\hline 1126 & 65.314 & 300.682 & 20.0143 & 0.22362 & 0.053890 .001 & 298.219 & $0.776 \times 10^{-7} 0.007$ & 34.7 \\
\hline 1127 & 65.306 & 301.000 & 19.9942 & 0.25163 & 0.053760 .001 & 298.224 & $0.770 \times 10^{-7} 0.006$ & 34.9 \\
\hline 1128 & 65.299 & 301.327 & 19.9738 & 0.28120 & 0.053700 .001 & 298.217 & $0.770 \times 10^{-7} 0.005$ & 34.9 \\
\hline 1129 & 65.290 & 301.675 & 19.9519 & 0.31240 & 0.053670 .001 & 298.244 & $0.770 \times 10^{-7} 0.005$ & 34.9 \\
\hline 1130 & 65.282 & 302.034 & 19.9296 & 0.34525 & 0.053640 .000 & 298.232 & $0.771 \times 10^{-7} 0.004$ & 34.8 \\
\hline 1131 & 65.273 & 302.431 & 19.9049 & 0.37948 & $0.05352 \quad 0.001$ & 298.212 & $0.767 \times 10^{-7} 0.005$ & 35.0 \\
\hline 1132 & 65.265 & 302.841 & 19.8796 & 0.41638 & 0.053430 .000 & 298.206 & $0.762 \times 10^{-7} 0.004$ & 35.2 \\
\hline 1133 & 65.220 & 302.836 & 19.8731 & 0.41590 & 0.053460 .000 & 298.170 & $0.775 \times 10^{-7} 0.004$ & 34.6 \\
\hline 1134 & 65.213 & 302.439 & 19.8953 & 0.37977 & 0.053470 .000 & 298.182 & $0.776 \times 10^{-7} 0.004$ & 34.6 \\
\hline 1135 & 65.207 & 302.037 & 19.9180 & 0.34562 & 0.053570 .000 & 298.201 & $0.777 \times 10^{-7} \quad 0.004$ & 34.5 \\
\hline 1136 & 65.200 & 301.673 & 19.9383 & 0.31300 & 0.053660 .001 & 298.244 & $0.776 \times 10^{-7} 0.005$ & 34.6 \\
\hline 1137 & 65.191 & 301.313 & 19.9583 & 0.28163 & 0.053720 .001 & 298.227 & $0.777 \times 10^{-7} 0.005$ & 34.6 \\
\hline 1138 & 65.185 & 300.992 & 19.9762 & 0.25205 & 0.053720 .001 & 298.244 & $0.772 \times 10^{-7} 0.006$ & 34.8 \\
\hline 1139 & 65.176 & 300.680 & 19.9934 & 0.22382 & 0.053770 .001 & 298.224 & $0.771 \times 10^{-7} 0.007$ & 34.8 \\
\hline 1140 & 65.170 & 300.369 & 20.0108 & 0.19759 & 0.053850 .001 & 298.162 & $0.769 \times 10^{-7} 0.008$ & 35.0 \\
\hline 1141 & 65.164 & 300.101 & 20.0259 & 0.17300 & 0.053880 .001 & 298.207 & $0.765 \times 10^{-7} 0.009$ & 35.1 \\
\hline 1142 & 65.159 & 299.841 & 20.0405 & 0.14996 & 0.053890 .001 & 298.195 & $0.760 \times 10^{-7} 0.011$ & 35.3 \\
\hline 1143 & 65.154 & 299.607 & 20.0537 & 0.12861 & 0.054040 .002 & 298.214 & $0.760 \times 10^{-7} 0.014$ & 35.5 \\
\hline 1144 & 65.146 & 299.385 & 20.0658 & 0.10884 & $0.05402 \quad 0.002$ & 298.173 & $0.733 \times 10^{-7} 0.017$ & 36.7 \\
\hline
\end{tabular}

Table 3. Thermal conductivity, thermal diffusivity, and heat capacity of nitrogen gas near $425 \mathrm{~K}$

\begin{tabular}{|c|c|c|c|c|c|c|c|c|}
\hline Run Pt. & $\begin{array}{c}\text { Pressure } \\
\mathrm{MPa}\end{array}$ & $\begin{array}{c}\text { Temperature } \\
\mathbf{K}\end{array}$ & $\begin{array}{c}\text { Density } \\
\mathrm{mol} / \mathrm{L}\end{array}$ & $\begin{array}{c}\text { Power } \\
W / m\end{array}$ & $\begin{array}{l}\text { Thermal } \\
\text { conductivity } \\
\text { W/(m/K) STAT }\end{array}$ & $\begin{array}{c}\text { Cell } \\
\text { temperature } \\
\mathbf{K}\end{array}$ & $\begin{array}{c}\text { Thermal } \\
\text { diffusivity } \\
\mathrm{m}^{2} / \mathrm{s} \text { DSTAT }\end{array}$ & $\begin{array}{c}\text { Specific } \\
\text { heat } \\
J /(\mathrm{mol} \cdot \mathrm{K})\end{array}$ \\
\hline 4001 & 67.472 & 426.243 & 13.0983 & 0.41718 & 0.060620 .001 & 421.862 & $0.122 \times 10^{-6} 0.008$ & 37.8 \\
\hline 4002 & 67.472 & 425.770 & 13.1098 & 0.37241 & 0.060620 .001 & 421.855 & $0.121 \times 10^{-6} 0.009$ & 38.1 \\
\hline 4003 & 67.471 & 425.332 & 13.1205 & 0.33045 & 0.060630 .001 & 421.844 & $0.122 \times 10^{-6} 0.011$ & 37.8 \\
\hline 4004 & 67.470 & 424.918 & 13.1305 & 0.29096 & 0.060590 .002 & 421.887 & $0.120 \times 10^{-6} 0.014$ & 38.1 \\
\hline 4005 & 58.114 & 426.577 & 11.9010 & 0.41738 & 0.056710 .001 & 421.881 & $0.125 \times 10^{-6} 0.008$ & 37.8 \\
\hline 4006 & 58.113 & 426.072 & 11.9128 & 0.37279 & 0.056720 .001 & 421.854 & $0.125 \times 10^{-6} 0.010$ & 37.8 \\
\hline 4007 & 58.113 & 425.597 & 11.9239 & 0.33059 & 0.056680 .001 & 421.851 & $0.124 \times 10^{-6} 0.011$ & 38.1 \\
\hline
\end{tabular}


Table 3. Thermal conductivity, thermal diffusivity, and heat capacity of nitrogen gas near $425 \mathrm{~K}$

\begin{tabular}{|c|c|c|c|c|c|c|c|c|}
\hline Run Pt. & $\begin{array}{c}\text { Pressure } \\
\mathrm{MPa}\end{array}$ & $\begin{array}{c}\text { Temperature } \\
\mathbf{K}\end{array}$ & $\begin{array}{l}\text { Density } \\
\mathrm{mol} / \mathrm{L}\end{array}$ & $\begin{array}{l}\text { Power } \\
W / m\end{array}$ & $\begin{array}{c}\text { Thermal } \\
\text { conductivity } \\
\mathrm{W} /(\mathrm{m} \cdot \mathrm{K}) \mathrm{STAT}\end{array}$ & $\begin{array}{c}\text { Cell } \\
\text { temperature } \\
\text { K }\end{array}$ & $\begin{array}{c}\text { Thermal } \\
\text { diffusivity } \\
\mathrm{m}^{2} / \mathrm{s} \text { DSTAT }\end{array}$ & $\begin{array}{l}\text { Specific } \\
\text { heat } \\
\mathrm{J} /(\mathrm{mol} \cdot \mathrm{K})\end{array}$ \\
\hline 4008 & 58.112 & 425.159 & 11.9341 & 0.29111 & 0.056700 .001 & 421.932 & $0.124 \times 10^{-6} 0.013$ & 38.0 \\
\hline 4009 & 53.330 & 426.824 & 11.2302 & 0.41741 & 0.054720 .001 & 421.932 & $0.129 \times 10^{-6} 0.009$ & 37.5 \\
\hline 4010 & 53.331 & 426.299 & 11.2424 & 0.37276 & 0.054750 .001 & 421.896 & $0.129 \times 10^{-6} 0.008$ & 37.5 \\
\hline 4011 & 53.331 & 425.804 & 11.2537 & 0.33063 & 0.054730 .001 & 421.910 & $0.128 \times 10^{-6} 0.011$ & 37.6 \\
\hline 4012 & 53.330 & 425.351 & 11.2640 & 0.29114 & 0.054690 .001 & 421.893 & $0.128 \times 10^{-6} 0.012$ & 37.8 \\
\hline 4013 & 48.692 & 427.059 & 10.5387 & 0.41713 & 0.052820 .001 & 421.976 & $0.134 \times 10^{-6} 0.009$ & 36.9 \\
\hline 4014 & 48.692 & 426.504 & 10.5510 & 0.37264 & 0.052850 .001 & 421.986 & $0.134 \times 10^{-6} 0.009$ & 37.0 \\
\hline 4015 & 48.694 & 426.006 & 10.5622 & 0.33066 & 0.052780 .001 & 421.980 & $0.133 \times 10^{-6} 0.010$ & 37.2 \\
\hline 4016 & 48.695 & 425.535 & 10.5728 & 0.29113 & 0.052750 .001 & 421.999 & $0.132 \times 10^{-6} 0.012$ & 37.4 \\
\hline 4017 & 43.950 & 427.314 & 9.7851 & 0.41691 & 0.050900 .001 & 421.968 & $0.141 \times 10^{-6} 0.008$ & 36.3 \\
\hline 4018 & 43.950 & 426.757 & 9.7970 & 0.37232 & $0.05088 \quad 0.001$ & 422.007 & $0.141 \times 10^{-6} 0.008$ & 36.5 \\
\hline 4019 & 43.951 & 426.234 & 9.8081 & 0.33020 & 0.050820 .001 & 421.962 & $0.140 \times 10^{-6} 0.010$ & 36.5 \\
\hline 4020 & 43.952 & 425.736 & 9.8188 & 0.29078 & 0.050840 .001 & 421.988 & $0.142 \times 10^{-6} 0.012$ & 36.2 \\
\hline 4021 & 39.833 & 427.590 & 9.0889 & 0.41683 & 0.049180 .001 & 422.036 & $0.150 \times 10^{-6} 0.008$ & 35.6 \\
\hline 4022 & 39.833 & 426.999 & 9.1006 & 0.37243 & 0.049160 .001 & 422.048 & $0.149 \times 10^{-6} 0.009$ & 35.7 \\
\hline 4023 & 39.833 & 426.441 & 9.1120 & 0.33052 & $0.04915 \quad 0.001$ & 422.045 & $0.149 \times 10^{-6} 0.010$ & 35.8 \\
\hline 4024 & 39.833 & 425.924 & 9.1224 & 0.29100 & 0.049150 .001 & 422.039 & $0.150 \times 10^{-6} 0.012$ & 35.6 \\
\hline 4025 & 35.790 & 427.900 & 8.3645 & 0.41754 & 0.047570 .001 & 422.152 & $0.160 \times 10^{-6} 0.008$ & 34.9 \\
\hline 4026 & 35.790 & 427.305 & 8.3758 & 0.37311 & $0.04752 \quad 0.001$ & 422.153 & $0.160 \times 10^{-6} 0.008$ & 35.0 \\
\hline 4027 & 35.790 & 426.735 & 8.3864 & 0.33098 & 0.047490 .001 & 422.110 & $0.160 \times 10^{-6} 0.010$ & 35.0 \\
\hline 4028 & 35.790 & 426.179 & 8.3970 & 0.29138 & $0.04746 \quad 0.001$ & 422.150 & $0.158 \times 10^{-6} 0.012$ & 35.3 \\
\hline 4029 & 32.279 & 427.535 & 7.7127 & 0.37281 & 0.046130 .001 & 422.149 & $0.171 \times 10^{-6} 0.009$ & 34.5 \\
\hline 4030 & 32.278 & 426.922 & 7.7235 & 0.33073 & 0.046090 .001 & 422.178 & $0.169 \times 10^{-6} 0.010$ & 34.7 \\
\hline 4031 & 32.277 & 426.336 & 7.7338 & 0.29120 & 0.046090 .001 & 422.166 & $0.166 \times 10^{-6} 0.012$ & 35.5 \\
\hline 4032 & 32.277 & 425.813 & 7.7430 & 0.25423 & 0.046010 .001 & 422.149 & $0.163 \times 10^{-6} 0.013$ & 36.0 \\
\hline 4033 & 28.758 & 427.433 & 7.0199 & 0.37227 & $0.04475 \quad 0.001$ & 421.825 & $0.182 \times 10^{-6} 0.009$ & 34.5 \\
\hline 4034 & 28.758 & 426.811 & 7.0301 & 0.33032 & 0.044680 .001 & 421.816 & $0.179 \times 10^{-6} 0.010$ & 34.9 \\
\hline 4035 & 28.758 & 426.211 & 7.0400 & 0.29088 & $0.04468 \quad 0.001$ & 421.790 & $0.179 \times 10^{-6} 0.011$ & 35.0 \\
\hline 4036 & 28.758 & 425.639 & 7.0495 & 0.25398 & 0.044630 .001 & 421.822 & $0.176 \times 10^{-6} 0.013$ & 35.6 \\
\hline 4037 & 25.269 & 427.643 & 6.2935 & 0.37238 & 0.043360 .001 & 421.789 & $0.200 \times 10^{-6} 0.009$ & 33.9 \\
\hline 4038 & 25.269 & 426.975 & 6.3034 & 0.33045 & 0.043300 .001 & 421.785 & $0.197 \times 10^{-6} 0.010$ & 34.3 \\
\hline 4039 & 25.269 & 426.356 & 6.3127 & 0.29108 & 0.043290 .001 & 421.807 & $0.196 \times 10^{-6} 0.011$ & 34.5 \\
\hline 4040 & 25.268 & 425.804 & 6.3208 & 0.25421 & 0.043250 .001 & 421.784 & $0.195 \times 10^{-6} 0.013$ & 34.6 \\
\hline 4041 & 22.030 & 427.617 & 5.5903 & 0.35533 & 0.042070 .001 & 421.789 & $0.222 \times 10^{-6} 0.009$ & 33.3 \\
\hline 4042 & 22.029 & 427.074 & 5.5975 & 0.32252 & $0.04206 \quad 0.001$ & 421.800 & $0.222 \times 10^{-6} 0.010$ & 33.3 \\
\hline 4043 & 22.029 & 426.577 & 5.6040 & 0.29091 & 0.042010 .001 & 421.786 & $0.221 \times 10^{-6} 0.011$ & 33.5 \\
\hline 4044 & 22.028 & 426.084 & 5.6105 & 0.26121 & $0.04198 \quad 0.001$ & 421.793 & $0.218 \times 10^{-6} 0.013$ & 33.8 \\
\hline 4045 & 19.120 & 427.585 & 4.9318 & 0.33856 & $0.04095 \quad 0.001$ & 421.825 & $0.246 \times 10^{-6} 0.010$ & 33.0 \\
\hline 4046 & 19.120 & 427.026 & 4.9385 & 0.30638 & 0.040900 .001 & 421.830 & $0.246 \times 10^{-6} 0.011$ & 33.0 \\
\hline 4047 & 19.120 & 426.514 & 4.9446 & 0.27586 & 0.040860 .001 & 421.829 & $0.244 \times 10^{-6} 0.012$ & 33.3 \\
\hline 4048 & 19.120 & 426.029 & 4.9504 & 0.24689 & $0.04086 \quad 0.001$ & 421.844 & $0.245 \times 10^{-6} 0.013$ & 33.3 \\
\hline 4049 & 16.150 & 427.870 & 4.2299 & 0.33858 & 0.039850 .001 & 421.893 & $0.281 \times 10^{-6} 0.009$ & 32.8 \\
\hline 4050 & 16.150 & 427.308 & 4.2357 & 0.30642 & 0.039820 .001 & 421.888 & $0.279 \times 10^{-6} 0.011$ & 33.1 \\
\hline 4051 & 16.150 & 426.767 & 4.2413 & 0.27587 & 0.039820 .001 & 421.892 & $0.280 \times 10^{-6} 0.012$ & 33.0 \\
\hline 4052 & 16.150 & 426.256 & 4.2466 & 0.24689 & 0.039790 .001 & 421.882 & $0.277 \times 10^{-6} 0.013$ & 33.3 \\
\hline 4053 & 13.434 & 427.860 & 3.5681 & 0.32224 & 0.038850 .001 & 421.902 & $0.332 \times 10^{-6} 0.011$ & 32.1 \\
\hline 4054 & 13.433 & 427.263 & 3.5731 & 0.29090 & 0.038800 .001 & 421.891 & $0.329 \times 10^{-6} 0.012$ & 32.4 \\
\hline 4055 & 13.433 & 426.739 & 3.5777 & 0.26115 & 0.038790 .001 & 421.927 & $0.328 \times 10^{-6} 0.012$ & 32.4 \\
\hline 4056 & 13.433 & 426.225 & 3.5820 & 0.23294 & 0.038730 .001 & 421.889 & $0.326 \times 10^{-6} 0.014$ & 32.7 \\
\hline 4057 & 10.616 & 428.169 & 2.8565 & 0.32218 & $0.03788 \quad 0.001$ & 421.961 & $0.404 \times 10^{-6} 0.011$ & 32.0 \\
\hline 4058 & 10.615 & 427.574 & 2.8603 & 0.29100 & $0.03784 \quad 0.001$ & 421.930 & $0.403 \times 10^{-6} 0.012$ & 32.1 \\
\hline 4059 & 10.615 & 427.001 & 2.8643 & 0.26120 & 0.037820 .001 & 421.955 & $0.405 \times 10^{-6} 0.014$ & 31.9 \\
\hline 4060 & 10.614 & 426.476 & 2.8678 & 0.23298 & 0.037820 .001 & 421.964 & $0.407 \times 10^{-6} 0.015$ & 31.8 \\
\hline
\end{tabular}


Journal of Research of the National Institute of Standards and Technology

Table 3. Thermal conductivity, thermal diffusivity, and heat capacity of nitrogen gas near $425 \mathrm{~K}-$ Continued

\begin{tabular}{|c|c|c|c|c|c|c|c|c|}
\hline Run Pt. & $\begin{array}{l}\text { Pressure } \\
\text { MPa }\end{array}$ & $\begin{array}{c}\text { Temperature } \\
\mathbf{K}\end{array}$ & $\begin{array}{l}\text { Density } \\
\mathrm{mol} / \mathrm{L}\end{array}$ & $\begin{array}{l}\text { Power } \\
W / m\end{array}$ & $\begin{array}{c}\text { Thermal } \\
\text { conductivity } \\
\mathrm{W} /(\mathrm{m} \cdot \mathrm{K}) \mathrm{STAT}\end{array}$ & $\begin{array}{c}\text { Cell } \\
\text { temperature } \\
\mathbf{K}\end{array}$ & $\begin{array}{c}\text { Thermal } \\
\text { diffusivity } \\
\mathrm{m}^{2} / \mathrm{s} \text { DSTAT }\end{array}$ & $\begin{array}{c}\text { Specific } \\
\text { heat } \\
\mathrm{J} /(\mathrm{mol} \cdot \mathrm{K})\end{array}$ \\
\hline 4061 & 8.185 & 428.204 & 2.2268 & 0.30620 & 0.037050 .001 & 421.986 & $0.511 \times 10^{-6} 0.012$ & 31.8 \\
\hline 4062 & 8.184 & 427.588 & 2.2299 & 0.27571 & 0.037010 .001 & 421.956 & $0.506 \times 10^{-6} 0.012$ & 32.1 \\
\hline 4063 & 8.184 & 427.013 & 2.2329 & 0.24678 & $0.03700 \quad 0.001$ & 421.992 & $0.509 \times 10^{-6} 0.014$ & 31.9 \\
\hline 4064 & 8.184 & 426.459 & 2.2359 & 0.21939 & 0.036960 .002 & 421.986 & $0.504 \times 10^{-6} 0.016$ & 32.2 \\
\hline 4065 & 5.684 & 428.304 & 1.5628 & 0.29076 & 0.036270 .001 & 422.071 & $0.732 \times 10^{-6} 0.012$ & 30.9 \\
\hline 4066 & 5.684 & 427.662 & 1.5650 & 0.26101 & 0.036250 .001 & 422.046 & $0.733 \times 10^{-6} 0.014$ & 30.9 \\
\hline 4067 & 5.683 & 427.047 & 1.5671 & 0.23291 & 0.036240 .001 & 421.984 & $0.714 \times 10^{-6} 0.016$ & 31.8 \\
\hline 4068 & 5.682 & 426.467 & 1.5692 & 0.20636 & $\begin{array}{lll}0.03621 & 0.002\end{array}$ & 422.052 & $0.714 \times 10^{-6} 0.017$ & 31.7 \\
\hline 4069 & 3.262 & 428.449 & 0.9050 & 0.27577 & 0.035630 .001 & 422.058 & $0.122 \times 10^{-5} 0.015$ & 31.5 \\
\hline 4070 & 3.260 & 427.778 & 0.9061 & 0.24681 & $0.03562 \quad 0.001$ & 422.127 & $0.122 \times 10^{-5} 0.016$ & 31.5 \\
\hline 4071 & 3.259 & 427.155 & 0.9071 & 0.21944 & 0.035610 .002 & 422.067 & $0.121 \times 10^{-5} 0.018$ & 31.8 \\
\hline 4072 & 3.258 & 426.571 & 0.9082 & 0.19367 & $0.03557 \quad 0.002$ & 422.071 & $0.122 \times 10^{-5} 0.020$ & 31.6 \\
\hline
\end{tabular}

obtain the isobaric heat capacity from the measured thermal diffusivity, we have calculated the density with the equation of state of Goodwin [14].

Figure 4 shows a typical deviation plot of the experimental temperature rises from the full heat transfer model for a liquid phase toluene point (number 1202) at a temperature of $324 \mathrm{~K}$. The deviations from linearity are less than $0.04 \%$. The deviations show that much of the noise is due to 60 $\mathrm{Hz}$ electromagnetic interference, but the noise is acceptably small. Table 1 shows two additional statistics which reflect nonlinearity of each data set relative to the ideal line source model, eq (1), after correcting according to eq (4). The first term is "STAT" which reflects the uncertainty in the slope of the regression line at a confidence level of 2 times the standard deviation $(2 \sigma)$. The term "DSTAT" reflects the uncertainty in the intercept of the regression line at a $2 \sigma$ confidence level. For instance, a value of "STAT" or "DSTAT" of 0.001 indicates the $2 \sigma$ uncertainty is $0.1 \%$. As discussed earlier, we expect the thermal radiation correction to affect the measured thermal conductivity of toluene more and more as the temperature is increased above $370 \mathrm{~K}$. The effect can be seen in the statistic "STAT" which is a numerical description of a deviation plot such as figure 4. Graphically, the deviation plots are no longer random but become systematically curved, as predicted by eq (11). Consequently, the thermal conductivities ob-

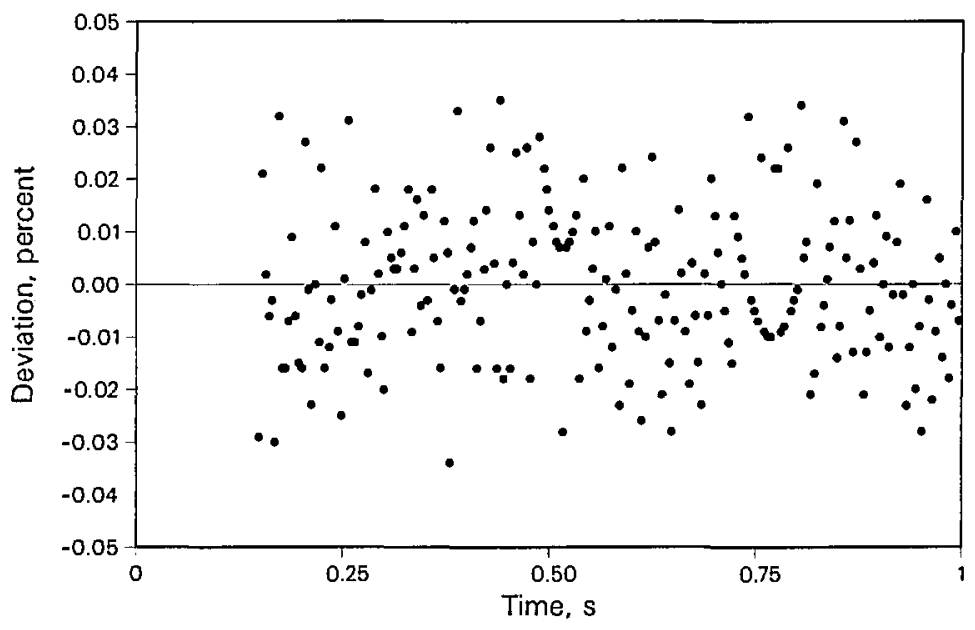

Figure 4. Typical deviations of experimental temperature rises from the calculated straight line versus the log of time for liquid toluene data point 1202 at $T_{0}=324.039 \mathrm{~K}$ and $P=0.088 \mathrm{MPa}$. 
tained from the usual linear fit are larger than they should be. To obtain correct results, we apply eq (12) to the experimentally measured temperature rises and evaluate $B$ for every individual point. Next, the experimentally determined values for $B$ are fit to a linear function in temperature. The resulting expression is

$$
B=-0.0685+2.310 \times 10^{-4} T_{0}
$$

where $B$ is in $\mathrm{s}^{-1}$ and $T_{0}$ is in $\mathrm{K}$. The values given by eq (15) are used to re-evaluate the radiation correction, $\delta T_{5}$, for each data point. The results corrected in this fashion are given in table 1.

Figure 5 shows the deviation plot for the temperature rises for a toluene data point (2105) at $T_{0}=548.140 \mathrm{~K}$ and $P=2.686 \mathrm{MPa}$, before and after the radiation correction $\delta T_{5}$ has been applied. The deviation "STAT" has decreased from 0.002 to 0.001 and the curvature has been eliminated. These
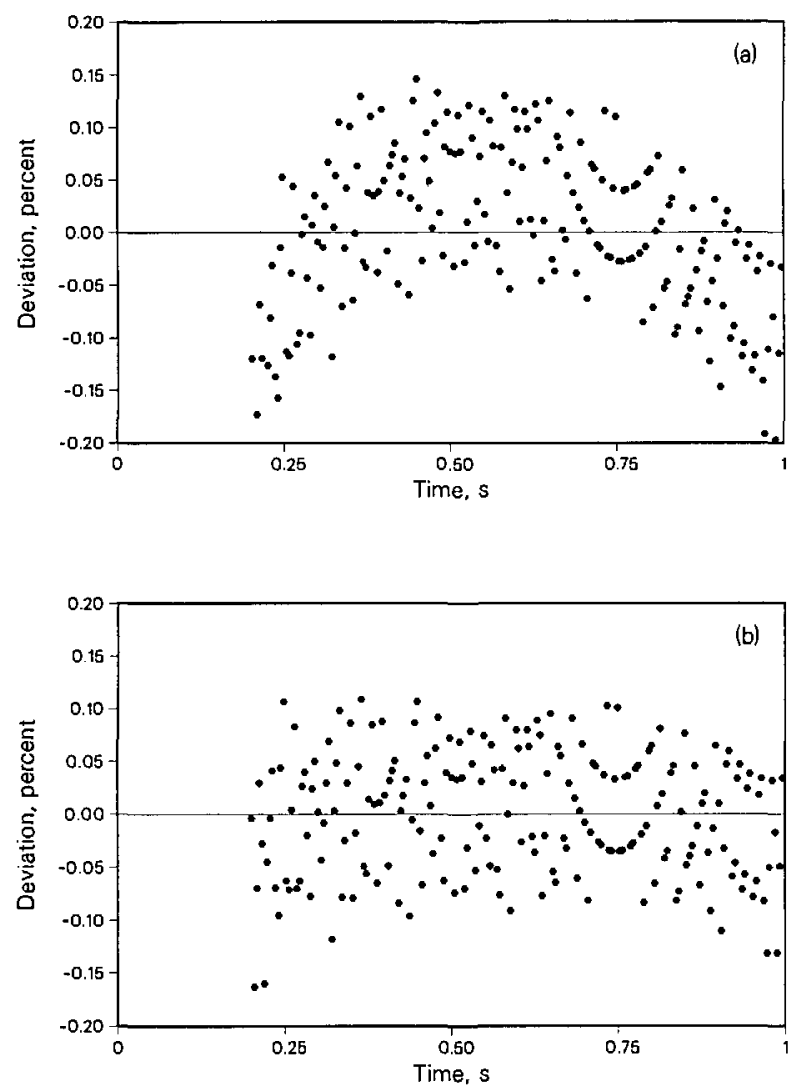

Figure 5. Liquid toluene data point 2105 at $T_{0}=548.140 \mathrm{~K}$ and $P=2.686 \mathrm{MPa}$.

a) before application of the radiation correction, eq (9), "STAT" is 0.002 .

b) after application of the radiation correction, eq (9), "STAT" is 0.001 . results support the model developed by Nieto de Castro et al. [7] to account for the effect of radiation in absorbing media, and suggest that the instrument with a revised $\delta T_{5}$ is operating in accordance with its mathematical model.

Figure 6 shows both the uncorrected and the radiation corrected thermal conductivity values of toluene near the saturation line as a function of temperature. The standard reference data correlation of Nieto de Castro et al. [13], which is valid to $360 \mathrm{~K}$, is a line shown in figure 8 . The measurements of Fischer and Obermeier [15] are also displayed. These were obtained with a rotating concentric-cylinder apparatus, operating in steadystate mode, for different gaps between the cylinders. We have included their extrapolation to zero gap, which is considered to be their radiation-corrected thermal conductivity. Figure 6 shows that our transient hot-wire instrument has a smaller radiation contribution than the steady-state measurements. However, the transient hot-wire radiation contribution becomes significant at elevated temperatures, $3.1 \%$ at $550 \mathrm{~K}$. The larger radiation contribution in steady-state methods produces much larger uncertainty in the extrapolated radiation-corrected thermal conductivity data obtained with steady-state instruments. The temperature dependence along the saturation boundary, shown in figure 6 , is similar to the trend reported in reference [13] with respect to the thermal conductivity data of Nieto de Castro et al. [7]. The data above $370 \mathrm{~K}$ show the presence of radiative effects. Also shown in figure 6 , as an insert, are the compressed-liquid data at $550 \mathrm{~K}$, which correspond to the shaded area of the diagram.

Deviations between the toluene thermal conductivity data and the correlation by Nieto de Castro et al. [13] are shown in figure 7 for temperatures up to $380 \mathrm{~K}$. All of the data are within $1 \%$ of the correlation from 300 to $372 \mathrm{~K}$; however, the deviations are systematic. We suggest that a higher-order temperature-dependent term might be added to the correlation in order to extend its temperature range.

Figure 8 displays the deviations between the heat capacity of toluene obtained from the measured thermal diffusivity and thermal conductivity using the density from the equation of state of Goodwin [14], versus the $C_{p}$ value calculated by this equation of state. The data, uncorrected for radiation, show systematic departures from the equation-of-state prediction above $370 \mathrm{~K}$, with deviations of $30 \%$ at $550 \mathrm{~K}$. After the adjusted radiation correction $\delta T_{5}$ is applied, the deviations decrease to less than $10 \%$ at the highest temperature, falling in a band of $\pm 5 \%$ 


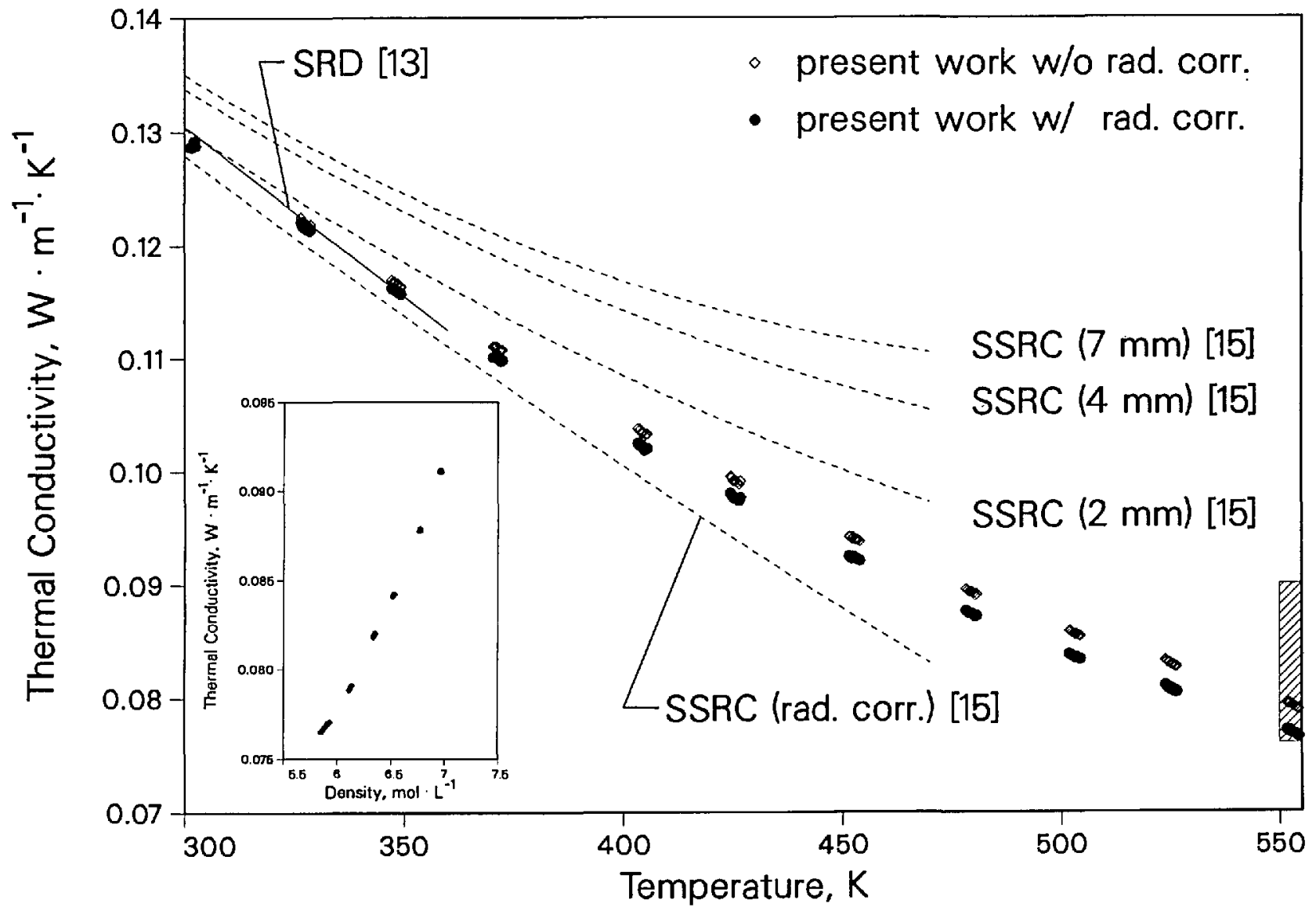

Figure 6. The thermal conductivity of liquid toluene near the saturation line. Dashed lines show steady-state rotating-cylinder (SSRC) results at various spacings along with the extrapolated radiation-corrected results. Solid line is the SRD correlation. The inset represents the thermal conduetivity of toluene as a function of density near $550 \mathrm{~K}$. The region of the inset is shaded on the main figure.

up to $500 \mathrm{~K}$. The larger deviations above $500 \mathrm{~K}$ are still within the combined uncertainties of our diffusivity measurements and the equation of state of Goodwin [14].

Figures 6 and 8 demonstrate the performance of the instrument for the measurement of both thermal conductivity and thermal diffusivity at high temperatures in infrared absorbing fluids when the radiation correction, given by eqs (9) to (13) and (15), is applied.

\subsection{Argon}

We have previously reported two sets of transient hot-wire measurements of argon's thermal conductivity near $300 \mathrm{~K}[16,17]$. Both of these data sets were made with the low temperature instrument described by Roder [8]. Thermal conductivity measurements on argon have also been reported by a number of other researchers [18-22]. Table 2 provides the results for the present measurements near $300 \mathrm{~K}$. Younglove's equation of state [23] is used to obtain the densities reported in the table 2. The purity of the argon used in these measurements is better than $99.999 \%$. Argon is transparent to thermal radiation, and the radiation correction at $300 \mathrm{~K}$ is negligible.

Deviations between the present thermal conductivity data and the new surface fit of Perkins et al. [24] as a function of density are shown in figure 9. The maximum deviation between our present measurements and the correlation is $1.2 \%$ at the highest densities. The present data were not, however, used in the development of the thermal conductivity surface [24]. The same trend of deviations relative to the correlation is exhibited by the other available data. Our thermal conductivity data agree with the results of the other data within $\pm 1 \%$. All of the other data were made with transient hotwire instruments, with the exception of data from Michels et al. [19], which was obtained with a steady-state parallel-plate instrument. 


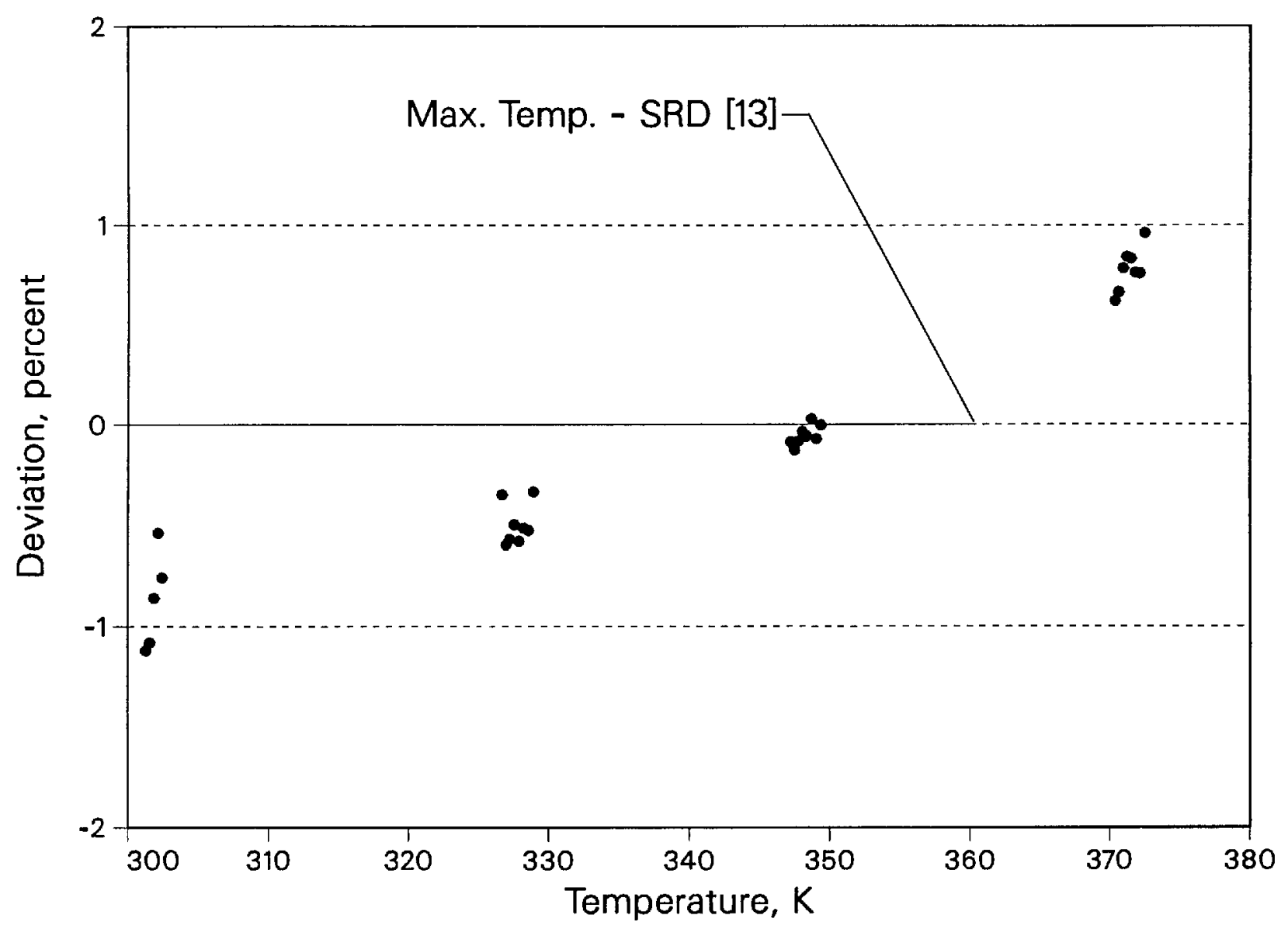

Figure 7. Deviation of liquid toluene thermal conductivity near saturation pressure relative to the correlation of Nieto de Castro et al. [13].

\subsection{Nitrogen}

For the present instrument, table 3 provides the results on nitrogen for temperatures near $425 \mathrm{~K}$. Younglove's equation of state [23] is used to obtain the densities reported in the table 3 . The purity of the nitrogen used in these measurements is better than $99.999 \%$. Nitrogen is transparent to thermal radiation, and the radiation correction at $425 \mathrm{~K}$ is negligible.

Deviations between our thermal conductivity data and the correlation of Stephan et al. [25] as a function of density are shown in figure 10 . The maximum deviation between our measurements and the correlation is $2 \%$. Nitrogen thermal conductivity measurements have also been reported by several other researchers $[21,22,26]$. The same trend of deviations relative to the correlation is exhibited by the other available data. Our thermal conductivity data agree with those results to $1 \%$, except for values from reference [22] for densities above $9 \mathrm{~mol} \cdot \mathrm{L}^{-1}$. All of the other data were ob- tained with transient hot-wire instruments, with the exception of data from le Neindre [22], which were obtained with a steady-state concentric-cylinder instrument. The dilute gas value of Millat and Wakeham [27] is also plotted in this figure and agrees with the extrapolation of the present data within $0.5 \%$. There is both theoretical [27] and experimental [28] evidence that the low density values of the Stephan et al. correlation [25] need to be revised. The correlation given by Younglove [23] has a completely different curvature as already shown in reference [28].

Figure 11 shows heat capacities of nitrogen given in table 3 for the isotherm at $425 \mathrm{~K}$. The values are derived from the measured values of thermal conductivity and thermal diffusivity taking the densities from the equation of state [23]. They are compared to values calculated from the equation of state, and they are systematically higher than the equation-of-state predictions by about $5 \%$ except for the highest densities. We assign an estimated error of $\pm 5 \%$ to our measured heat capacities; the 


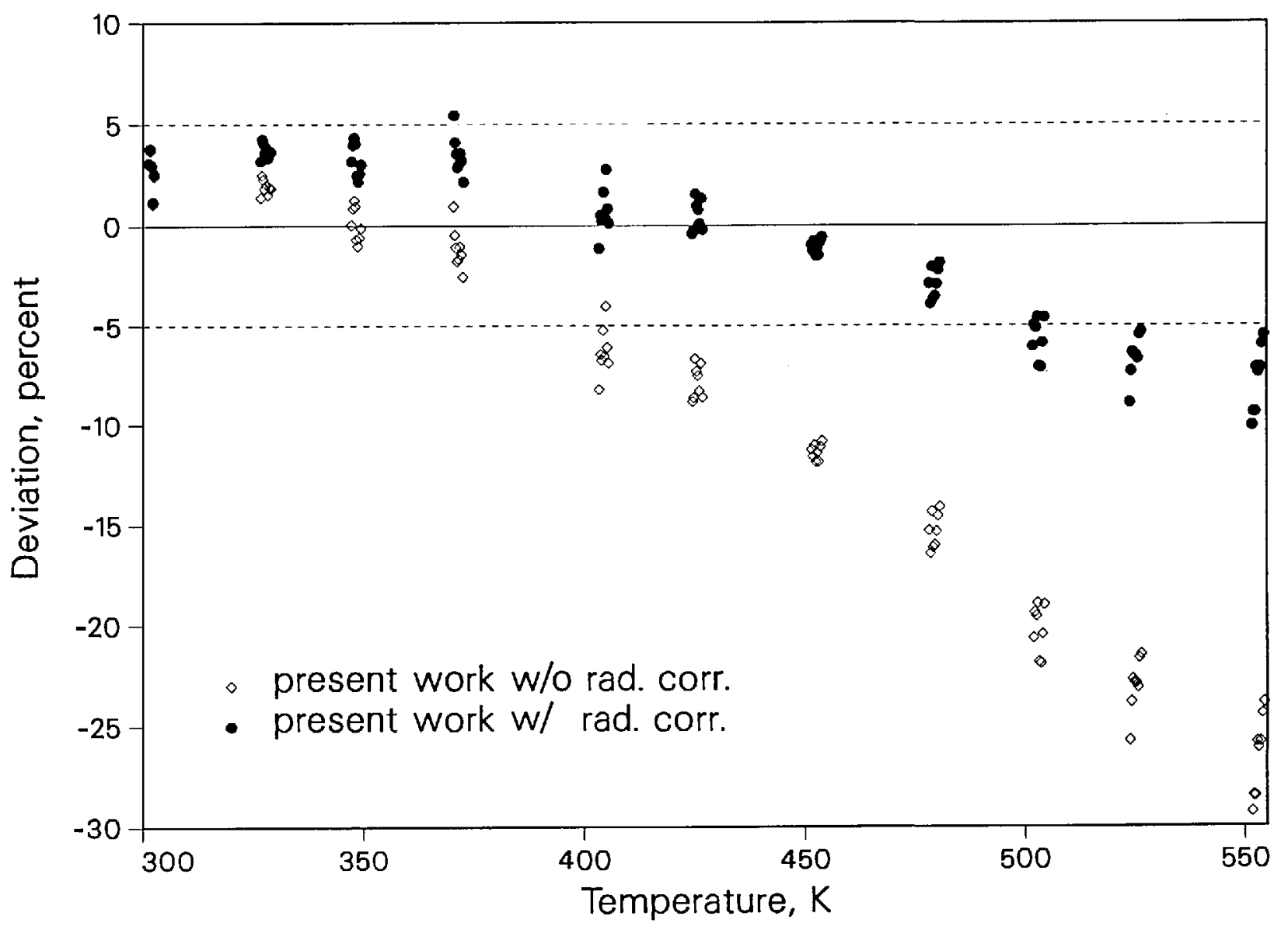

Figure 8. Deviation of liquid toluene isobaric heat capacity near saturation pressure relative to the $C_{p}$ calculated using the equation of state of Goodwin [14].

error estimated for the specific heats from the equation of state is also $5 \%$. Thus, the agreement between the two sources is within their mutual uncertainties even at the higher densities.

\subsection{Repeatability Tests}

In addition to comparisons of our thermal conductivity data with the data and correlations of other researchers, we have made many measurements to assess the repeatability of the instrument. The temperature assigned to a given thermal conductivity measurement is a function of the fluid temperature rise during the experiment. As a result, each power represents a different and independent temperature rise and experimental temperature. For a given cell temperature, we routinely make measurements at many powers not only to verify the instrument performance but also to check on the presence of convection. To check repeatability, results at different powers are compared in terms of deviations from a correlation of the thermal conductivity surface. Figure 12 shows deviations of the liquid toluene thermal conductivity data for four cell temperatures as a function of the applied power. There are from five to eight different powers for each cell temperature. The maximum difference between the deviations for each cell temperature is about $0.3 \%$, which is equivalent to the experimental precision in $\lambda$. The deviations do not appear to have any power dependence.

The power dependence of the isobaric heat capacity of liquid toluene is shown in figure 13. The maximum difference between the deviations for each temperature is $2.6 \%$. Again there is no discernable trend in the deviations of the heat capacity with respect to the applied power.

Figure 14 shows a deviation plot of 40 argon thermal conductivity data points relative to the correlation of Younglove et al. [29]. The applied power ranges from 0.11 to $0.42 \mathrm{~W} / \mathrm{m}$ for a range of final temperature rises from 0.8 to $5 \mathrm{~K}$. The data were obtained in four different sequences over 2 days. The four measurement sequences are shown 


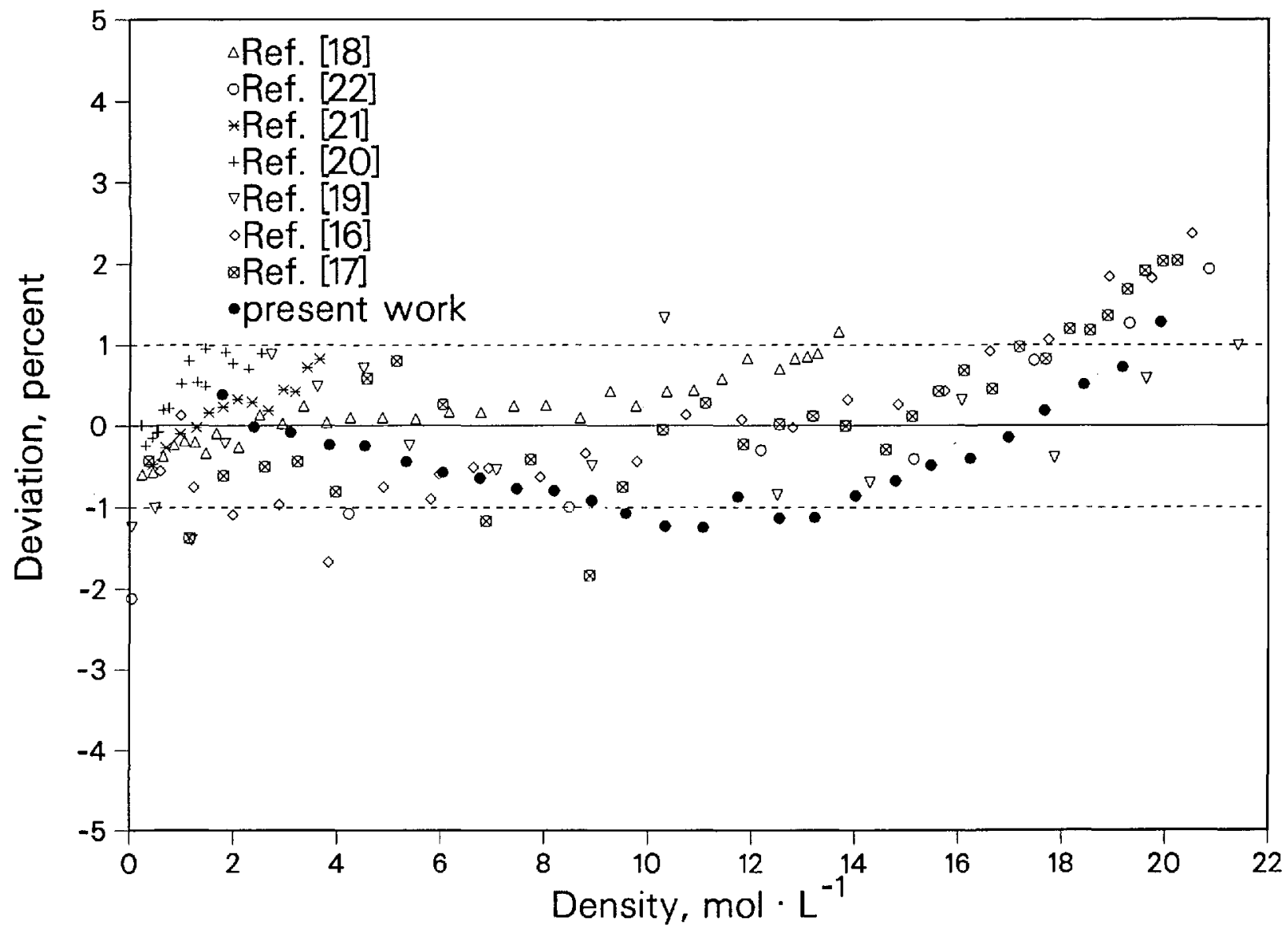

Figure 9. Deviations of argon thermal conductivity data near $300 \mathrm{~K}$ relative to the correlation of Perkins et al. [24].

with different plot symbols. The deviations from the correlation range from about $-0.1 \%$ to $-0.7 \%$. Thus, the set of 40 measurements are consistent with each other and fall within a band of $\pm 0.3 \%$. The instrument's response is shown to be independent of applied power over a very wide range of temperature rises. The instrument's performance is also very repeatable over an extended period.

\section{Summary}

A new transient hot-wire thermal conductivity instrument for use at high temperatures is described. This instrument has an operating range from 220 to $750 \mathrm{~K}$ at pressures to $70 \mathrm{MPa}$. Thermal conductivity can be measured over a wide range of fluid density, from the dilute gas to the compressed liquid. The thermal conductivity data have a precision of $\pm 0.3 \%$ and an accuracy of $\pm 1 \%$. The instrument is also capable of measuring the thermal diffusivity with a precision of $\pm 3 \%$ and an accuracy of $\pm 5 \%$. Given accurate fluid densities, we can obtain isobaric heat capacities from the data. This instrument complements our low temperature instrument [8] which has a temperature range from 80 to $325 \mathrm{~K}$ at pressures to $70 \mathrm{MPa}$. A detailed analysis of the influence of radiative heat transfer in the transient hot-wire experiment has been performed, and radiation-corrected thermal conductivities are reported for liquid toluene near saturation at temperatures between 300 and $550 \mathrm{~K}$. In addition, new measurements of the thermal conductivity and thermal diffusivity of argon and nitrogen verify the performance of the apparatus. 


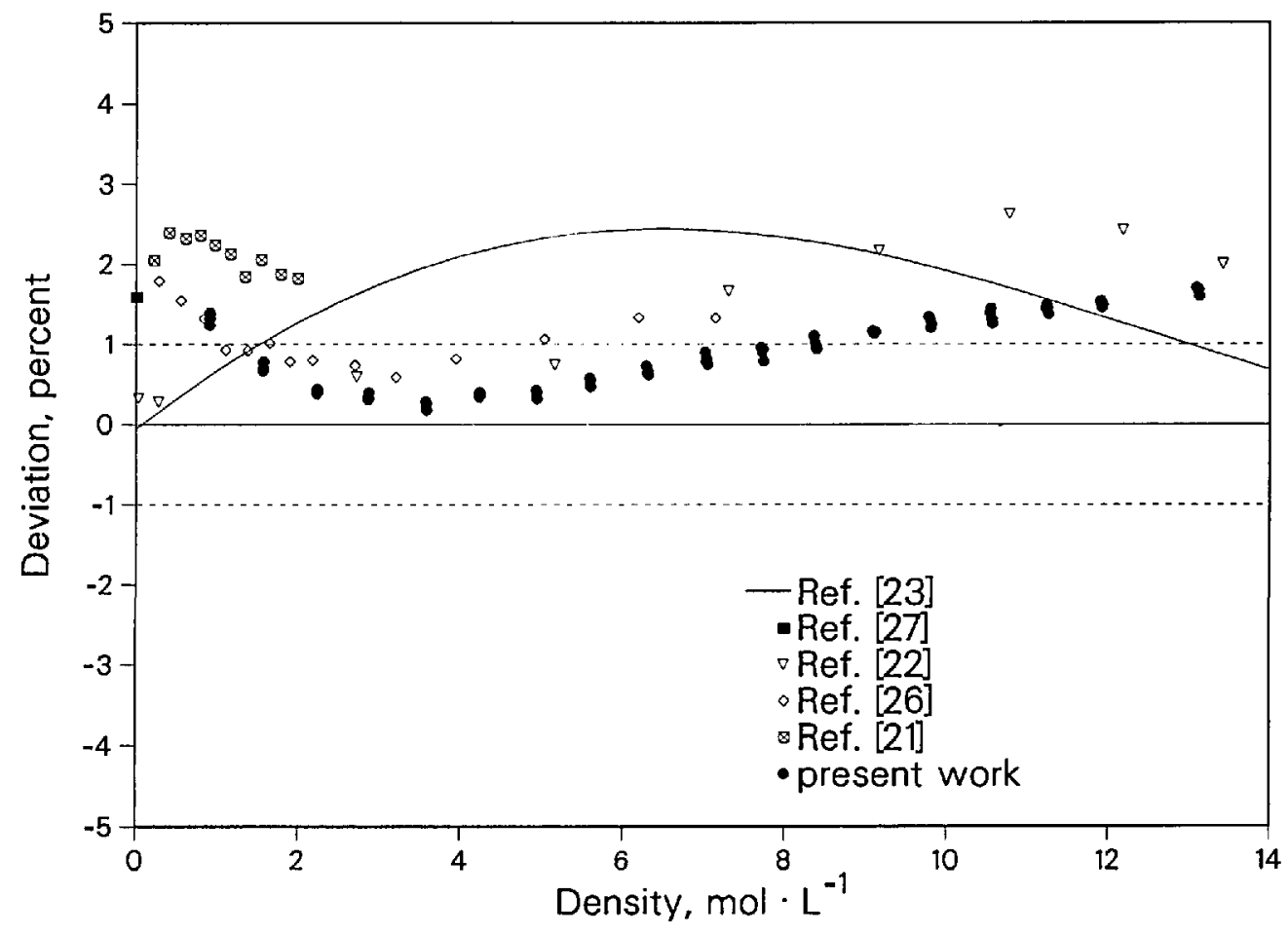

Figure 10. Deviations of nitrogen thermal conductivity near $428 \mathrm{~K}$ relative to the correlation of Stephan et al. [25].

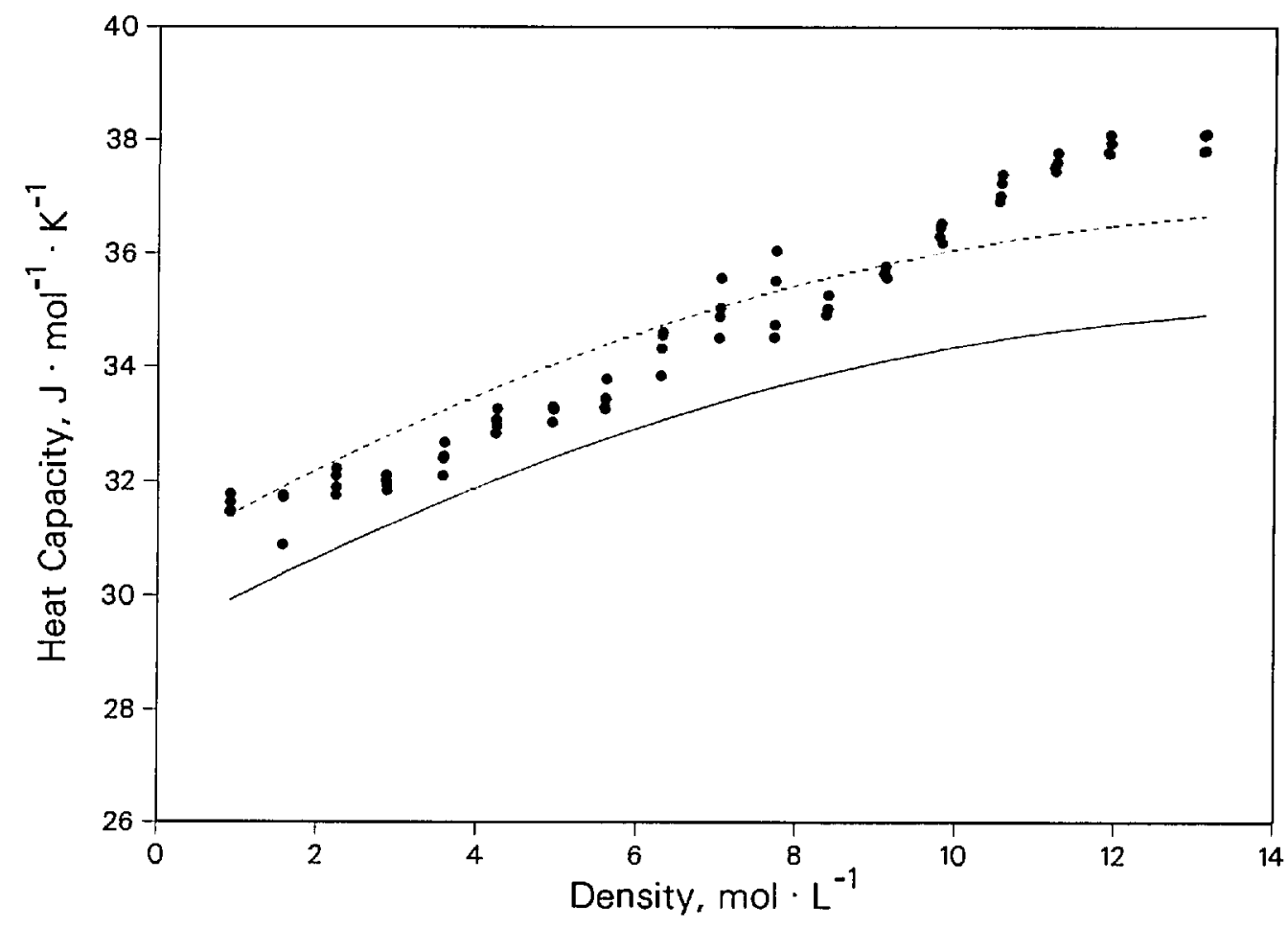

Figure 11. Nitrogen isobaric heat capacity relarive to values calculated (solid line) from the equation of state of Younglove [23]. Dashed line is a 5\% offset from [23]. 


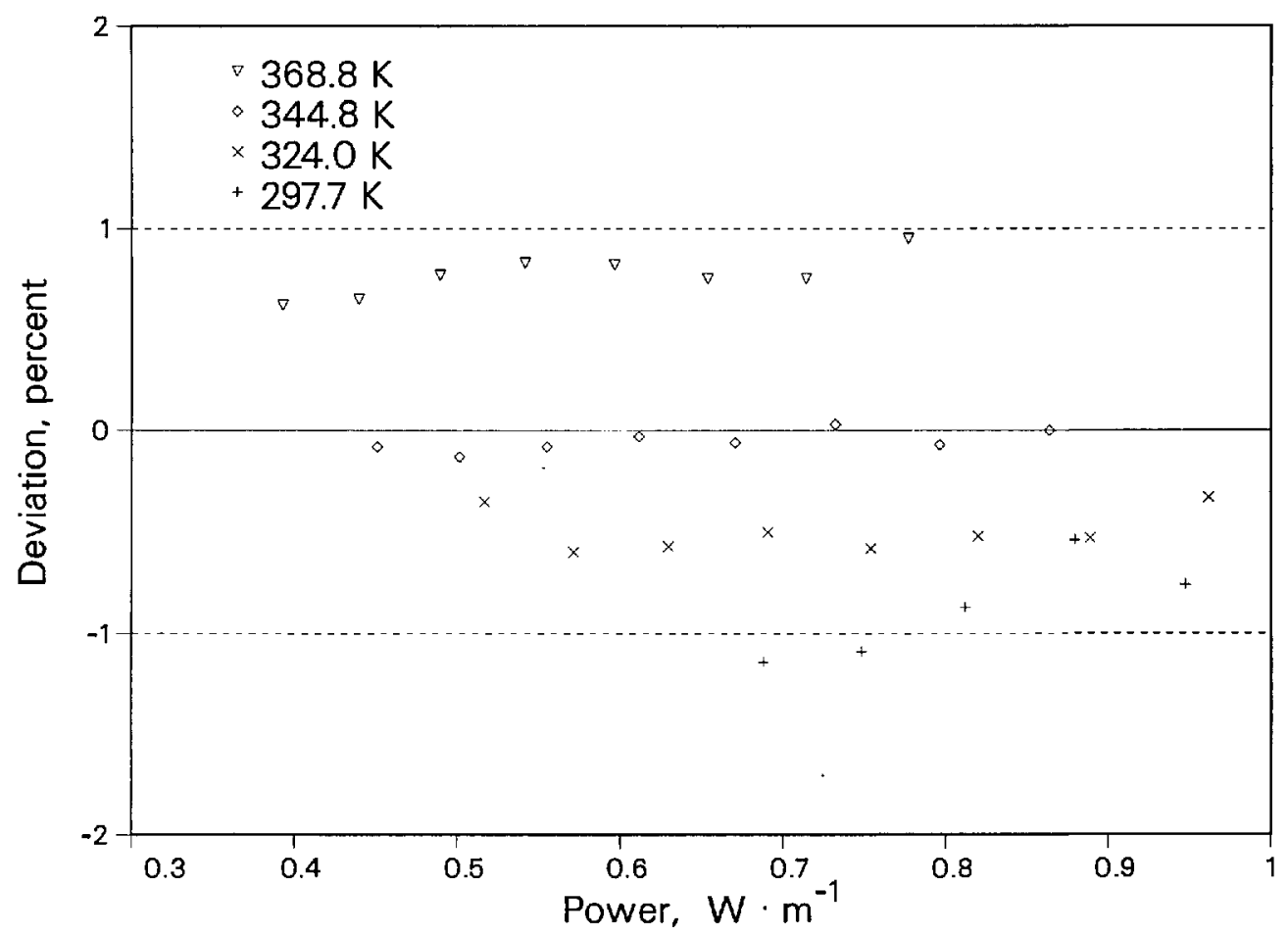

Figure 12. Deviations in the thermal conductivity of liquid toluene as a function of applicd power. Baseline is the correlation of Nieto de Castro ct al. [13]. Dashed lines show 95\% uncertainty band.

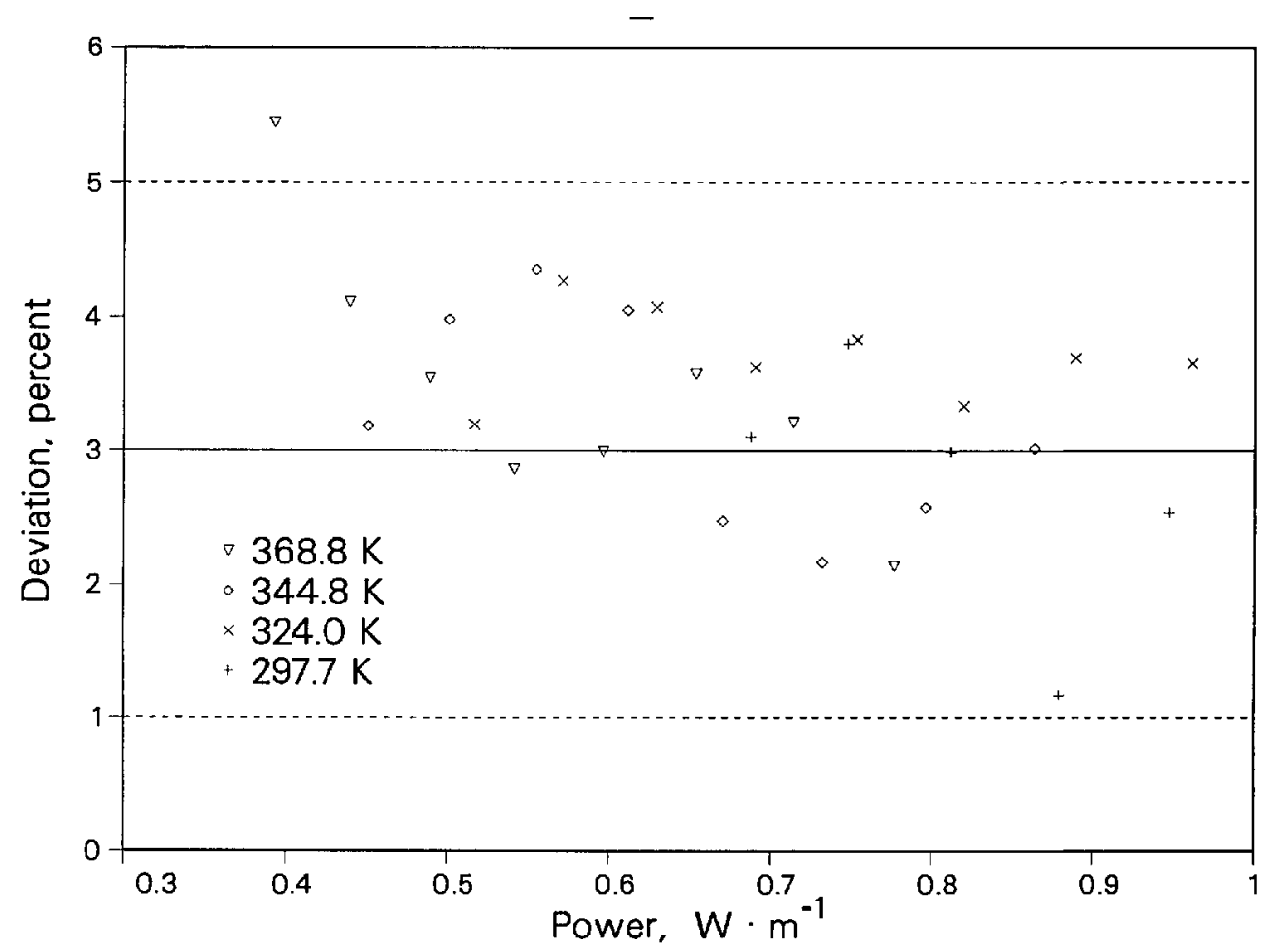

Figure 13. Deviations in the isobaric heat capacity of liquid toluene as a function of applied power. Baseline is the equation of state of Goodwin [14]. Dashed lines show 95\% uncertainty band. 


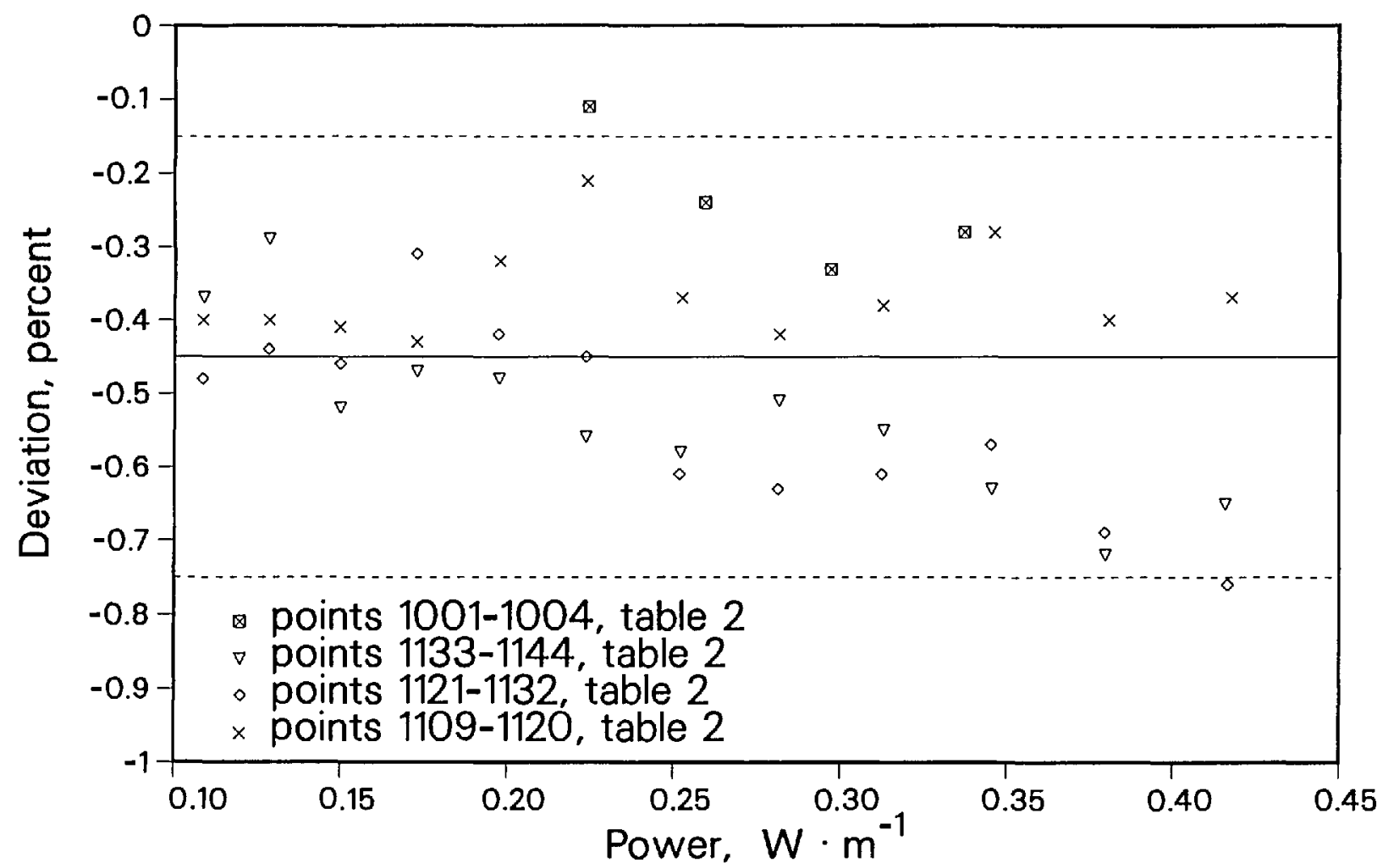

Figure 14. Deviations in the thermal conduetivity of argon gas as a funetion of applied power. Baseline is the correlation of Younglove et al. [29]. Dashed lines show 95\% uneertainty band.

\section{Acknowledgments}

We gratefully acknowledge the financial support of this work by the United States Department of Energy, Division of Chemical Sciences, Office of Basic Energy Sciences. One of the authors (C.A.N.C) thanks the Faculty of Sciences of the University of Lisbon for a leave of absence and the Thermophysics Division of the National Institute of Standards and Technology for a Guest Researchership.

\section{References}

[1] Nicto de Castro, C. A., JSME 1nter. J. 31, 387 (1988).

[2] Nieto de Castro, C. A., Taxis, B., Roder, H. M., and Wakeham, W. A., 1nt. J. Thermophys. 9, 293 (1988).

[3] Carslaw, H. S., and Jaeger, J. C., Conduetion of heat in solids, 2nd ed., Oxford University Press, London (1959).

[4] Healy, J. J., de Groot, J. J., and Kestin, J., Physiea 82C, 392 (1976).

[5] Siegel, R., and Howell, J. R., Thermal radiation heat transfer, 2nd ed., Hemisphere Publishing, New York (1981).

[6] Touloukian, Y. S., and DeWitt, D. P., Thermal radiative properties-metallic elements and alloys, Plenum Press, New York (1970).
[7] Nicto de Castro, C. A., Li, S. F., Maitland, G. C., and Wakeham, W. A., Int. J. Thermophys. 4, 311 (1983).

[8] Roder, H. M., J. Res. Natl. Bur. Stand. (U.S.) 86, 457 (1981).

[9] Roder, H. M., in Proe. 5th Symposium on Energy and Engineering Seienees, Dept. of Energy (U.S.) CONF-870687 (1987) p. 61.

[10] Roder, H. M., and Nieto de Castro, C. A., Cryogenies 27, 312 (1987).

[11] Roder, H. M., and Nieto de Castro, C. A., in Thermal Conductivity 20, Hasselman, D. P. H., and Thomas, J.R., Jr., eds., Plenum Press, New York (1989) p. 173.

[12] Roder, H. M., and Perkins, R. A., J. Res. Natl. Inst. Stand. Teehnol. 94, 1 (1989).

[13] Nieto de Castro, C. A., Li, S. F. Y., Nagashima, A., Trengove, R. D., and Wakeham, W. A., J. Phys. Chem. Ref. Data 15, 1073 (1986).

[14] Goodwin, R. D., J. Phys. Chem. Ref. Data 18, 1565 (1989).

[15] Fiseher, S., and Obermeier, E., High Temp. High Press. 17, 699 (1985).

[16] Nieto de Castro, C. A., and Roder, H. M., J. Res. Natl. Bur. Stand. (U.S.) 86, 193 (1981).

[17] Roder, H. M., Perkins, R. A., and Nieto de Castro, C. A., 1nt. J. Thermophys. 10, 1141 (1989).

[18] Kestin, J., Paul, R., Clifford, A. A., and Wakeham, W. A., Physica 100A, 349 (1980)

[19] Michels, A., Sengers, J. V., and Van de Klundert, L. J. M., Physica 29, 149 (1963).

[20] Millat, J., Ross, M. J., and Wakeham, W. A., Physica 159A, 28 (1989). 
[21] Haran, E. N., Maitland, G. C., Mustafa, M., and Wakeham, W. A., Ber. Bunsenges. Phys. Chem. 87, 657 (1983).

[22] le Neindre, B., Int. J. Heat Mass Transfer 15, 1 (1972).

[23] Younglove, B. A., J. Phys. Chem. Ref. Data 11, Suppl. 1 (1982).

[24] Perkins, R. A., Roder, H. M., Friend, D. G., and Nieto de Castro, C. A., Int. J. Thermophys. (1991) in press.

[25] Stephan, K., Krauss, R., and Laeseeke, A., J. Phys. Chem. Ref. Data 16, 993 (1987).

[26] Johns, A. I., Rashid, S., Watson, J. T. R., and Clifford, A. A., J. Chem. Soc. Faraday Trans. I 82, 2235 (1986).

[27] Millat, J., and Wakeham, W. A., J. Phys. Chem. Ref. Data 18, 565 (1989).

[28] Perkins, R. A., Roder, H. M., Friend, D. G., and Nieto de Castro, C. A., Physica A, In Press (1991).

[29] Younglove, B. A., and Hanley, H. J. M., J. Phys. Chem. Ref. Data 15, 1323 (1986).

About the authors: Richard A. Perkins is a chemical engineer in the Thermophysics Division of the NIST Chemical Science and Technology Laboratory. Hans $M$. Roder is a retired physicist from the NIST Thermophysics Division. Carlos A. Nieto de Castro is the president of the chemistry department at University of Lisbon, Portugal, and was a Guest Researcher at NIST. 